\title{
ESTUDO CEFALOMÉTRICO DA PERDA DE \\ ANCORAGEM INFERIOR, DURANTE A FASE DE NIVELAMENTO, NAS TÉCNICAS ARCO DE CANTO SIMPLIFICADA E ARCO RETO
}

RENATO MARZARI

Dissertação apresentada à Faculdade de Odontologia de Bauru, da Universidade de São Paulo, como parte dos requisitos para a obtenção do título de Mestre em Odontologia, área de Ortodontia.

\section{BAURU}




\section{ESTUDO CEFALOMÉTRICO DA PERDA DE \\ ANCORAGEM INFERIOR, DURANTE A FASE DE NIVELAMENTO, NAS TÉCNICAS ARCO DE CANTO SIMPLIFICADA E ARCO RETO}

\section{RENATO MARZARI}

Dissertação apresentada à Faculdade de Odontologia de Bauru, da Universidade de São Paulo, como parte dos requisitos para a obtenção do título de Mestre em Odontologia, área de Ortodontia.

(Edição Revista)

Orientador :

Prof.Dr. Marcos Roberto de Freitas

\section{BAURU}

1998 
Marzari, Renato

M369e Estudo cefalométrico da perda de ancoragem inferior, durante a fase de nivelamento, nas técnicas arco de canto simplificada e arco reto / Renato Marzari.

-- Bauru, 1998.

99p. : il. ; $30 \mathrm{~cm}$.

Dissertação. (Mestrado) -- Faculdade de Odontologia de Bauru. USP.

Orientador : Prof. Dr. Marcos Roberto de Freitas 
03 de Agosto de 1972

Nascimento

Bauru - SP

$1990-1993$

Curso de Graduação em Odontologia na Faculdade de Odontologia de Ribeirão Preto da Universidade de São Paulo

$1995-1998$

Curso de Pós-graduação em Odontologia, área de Ortodontia, ao nivel de Mestrado, na Faculdade de Odontologia de Bauru da Universidade de São Paulo

1998

Professor Assistente de Ortodontia do Curso de Odontologia da Universidade do Sagrado Coração

Associações

IADR - International Association for Dental Research SBPqO Sociedade Brasileira de Pesquisa Odontológica 
\|U ma palavra tem a força e o valor daquele que a pronuncia. A palavra humana pode errar e enganar, pois o homem é fraco. Mas a palavra de Deus não erra, nem engana. Ela cura, liberta e sustenta a vida de quem, por ela, se orienta." 


\section{Dedicatória}

A Deus, esse amigo de todas as horas, cheio de infinita bondade e que tanto me ilumina.

Aos meus pais Decio e Wanda, pela formação única de vida que me deram e por estarem presentes, atentos e zelosos em todos os momentos, sempre com amor.

Às minhas adoráveis irmãs, Marcia, Maria Angélica, Margarete e Maria Bernadete, por entenderem e me ajudarem nas mais diferentes situações, sempre dispostas a partilhar nossas ansiedades, nossas realidades e nossos sonhos. 


\section{Agradecimento em especial}

À Mariza, amor da minha vida, por todo carinho e companheirismo que imperam entre nós. 


\section{Agradecimentos}

Ao meu orientador Professor Doutor Marcos Roberto de Freitas, por toda confiança em mim depositada e por dar-me a chance de seguir nesta honrosa profissão. A ele, o meu eterno agradecimento.

Ao Professor Doutor Arnaldo Pinzan por possibilitar o meu ingresso na carreira docente, onde colocarei em prática todos os ensinamentos obtidos durante o curso de Mestrado.

Ao Professor Doutor Decio Rodrigues Martins, pela dedicação em nos formar bons profissionais e pelos exemplos de disciplina, conduta e amizade faz-me orgulhar de poder ter sido seu aluno.

Ao Professor Doutor José Fernando Castanha Henriques, pela aceitação de minha pessoa para frequentar o curso de Mestrado e também pela luta constante em manter o ótimo nível do curso de Mestrado em Ortodontia.

Ao Professor Doutor Renato Rodrigues de Almeida, pelas oportunidades concedidas e por minha formação pós-universitária.

Ao Professor Doutor Guilherme dos Reis Pereira Janson, pelo espirito jovem e sempre presente nos ensinamentos transmitidos ao longo do curso de Mestrado. 
Ao Professor Doutor Helio Scavone Junior, amigo e mestre que muito contribuiu para o meu crescimento profissional, dedicando-se incansavelmente.

À Professora Doutora Maria Fidela de Lima Navarro, pela amizade e empenho sempre demonstrados a mim.

À Cybelle Assumpção Fontes, pela prestimosa correção do rigor das normas bibliográficas.

À designer Ana Cláudia Aparecida Batista, por toda a linguagem gráfica da minha dissertação.

Ao Prof. Dr. Manuel Henrique Salgado, docente do Departamento de Engenharia de Produção da UNESPBauru, pelo valioso auxílio na avaliação estatística.

Ao Professor Mário Dimas Carpi, pela apurada e corretíssima revisão ortográfica.

Aos amigos do curso de Mestrado, Ana Patrícia Forero León, Cláudia Catão, Galdino Iague Neto, Graziela De Luca Canto, Júlio Vargas Neto, Letícia Fabbrizzi Souza, Liliana Ávila Maltagliati, Marcio Rodrigues de Almeida, Nicolás Zaragoza Velásquez, Ricardo Takahashi e Suzi Nakamura Santos. 


\section{Agradeço ainda ...}

À equipe de professores de Ortodontia da USC : Doutores Arnaldo Pinzan, Eduardo Alvares Dainesi, Júlio de Araújo Gurgel, Roberto Kawakami e às Doutoras Fabíola Elias, Leda Francischone de Oliveira, Márcia Yuri Kawauchi e Patrícia Zambonato Freitas.

Aos sempre receptivos profissionais do Departamento de Ortodontia : a acolhedora Tia Maria, às mãos abençoadas do Sérgio, à eficiência da Vera, à simpatia da Cristina e aos sempre prestativos Cristiane e Daniel.

Aos profissionais da Biblioteca, sempre empenhados em proporcionar um ótimo ambiente para nossas consultas.

Aos profissionais da seção de Pós-graduação, sempre solicitos em nos atender, qualquer que seja a ocasião. 
Aos professores e profissionais da Clínica de Radiologia, pela amizade e pelo cuidado na obtenção das radiografias.

Aos profissionais da Acopen : Sônia, Simone, César e Walter.

Aos colegas da IXa Turma de Mestrado e Doutorado, que me auxiliaram durante o período em que permaneci no Setor de Emergência em Ortodontia.

Aos alunos do curso de Especialização em Ortodontia da USP.

A todos os alunos do $2^{-}$ano do curso de Fonoaudiologia e $4^{0}$ ano de Odontologia da Universidade do Sagrado Coração.

Aos meus pacientes, que tanto me auxiliaram para a compreensão dos ensinamentos ortodônticos.

A todos os que, de alguma forma, estiveram presentes durante estes três anos de curso e que contribuíram para a realização desta dissertação. 


\section{Agradecimentos Institucionais}

Aos Professores Doutores Luiz Fernando Pegoraro, presidente da Comissão de Pós-graduação e José Carlos Pereira, ex-presidente da Comissão de Pós-graduação da Faculdade de Odontologia de Bauru, que atuaram de forma íntegra e decisiva para o melhor aproveitamento do curso.

Aos Professores Doutores Aymar Pavarini, Dignísimo Diretor da Faculdade de Odontologia de Bauru e Dagoberto Sottovia Filho, Digníssimo ExDiretor da Faculdade de Odontologia de Bauru, da Universidade de São Paulo.

Ao Professor Doutor Luís Casati Alvares, pela aceitação do meu nome para docente do Departamento de Odontologia da Universidade do Sagrado Coração.

À FAPESP, Fundação de Amparo à Pesquisa do Estado de São Paulo e à CAPES, Coordenação de Aperfeiçoamento de Pessoal de Nível Superior, pela concessão de recursos durante o curso. 


\section{SUMÁRIO}

RESUMO ............................................................ xii

1 INTRODUÇÃO ....................................................... 1

2 REVISÃO DE LITERATURA ....................................... 4

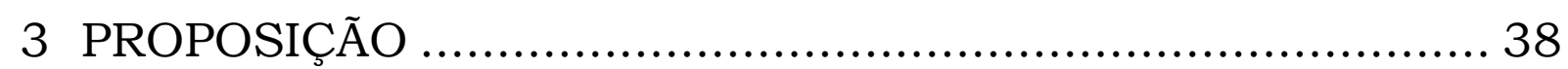

4 MATERIAL E MÉTODOS ....................................... 40

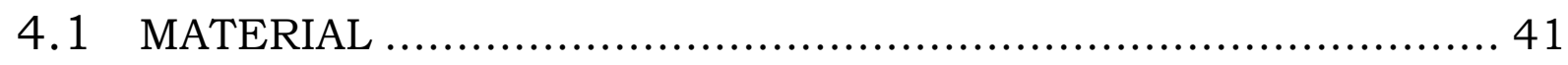

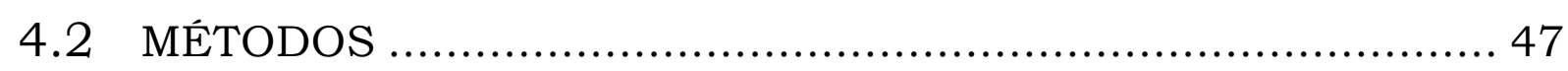

4.2.1 MÉTODO RADIOGRÁFICO ............................................. 47

4.2.2 MÉTODO CEFALOMÉTRICO .......................................... 48

4.2.2.1 Desenho anatômico ................................................. 49

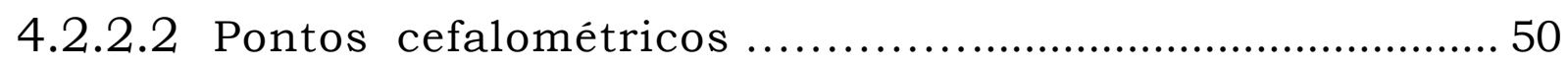

4.2.2.3 Linha e plano cefalométricos ................................ 53

4.2.2.4 Grandezas lineares ................................................ 53

4.2.3 MÉTODO ESTATÍSTICO ........................................... 56

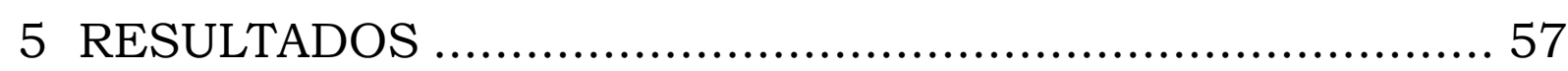

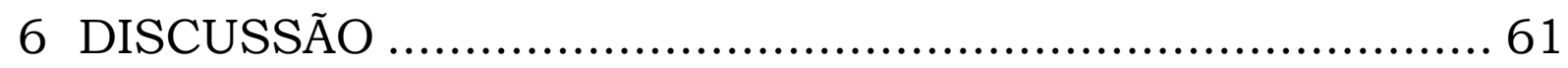

7 CONCLUSÕES ..................................................... 77

ANEXOS ......................................................... 79

REFERÊNCIAS BIBLIOGRÁFICAS ................................ 88

ABSTRACT ........................................................... 97 


\section{RESUMO}




\section{RESUMO}

$A_{\text {é um dos principais fatores para que a mecânica }}^{\text {o se realizar uma movimentacão dentária, a ancoragem }}$ ortodôntica seja empregada satisfatoriamente.

$\mathrm{Na}$ maioria das técnicas ortodônticas existentes, almeja-se uma mecânica eficiente que é diretamente proporcional à menor perda de ancoragem decorrente da técnica.

Nesta pesquisa, o objetivo foi comparar cefalometricamente a perda de ancoragem inferior durante a fase de nivelamento, em casos tratados com extrações dos primeiros pré-molares, nas técnicas do Arco de Canto Simplificada (Standard Edgewise) e Arco Reto (Straight wire), no que diz respeito ao posicionamento :

- Da coroa do primeiro molar inferior;

- Das raízes do primeiro molar inferior;

- Das coroas dos incisivos inferiores e

- Das raízes dos incisivos inferiores.

A amostra englobou as telerradiografias em norma lateral de 46 pacientes, obtidas ao início do tratamento e ao final da fase de nivelamento. Os pacientes foram distribuídos em dois grupos, de acordo com a técnica utilizada para a correção da má oclusão.

O grupo I abrangeu 27 pacientes nos quais a correção ortodôntica foi realizada pela técnica do Arco de Canto simplificada (Standard Edgewise), enquanto que o grupo II 
consistiu em 19 pacientes tratados ortodonticamente pela técnica do Arco Reto (Straight wire).

Sobre cada telerradiografia traçou-se um cefalograma específico para quantificar a movimentação dos dentes de ancoragem e dos incisivos. As grandezas cefalométricas utilizadas foram as distâncias lineares CM-C, RM-C, CI-C e RI-C.

Após a avaliação estatística e diante dos resultados obtidos, concluiu-se que durante a fase de nivelamento, comparando-se as técnicas Arco de Canto Simplificada e Arco Reto, ocorreu perda de ancoragem inferior nos dois grupos.

- A coroa do primeiro molar inferior apresentou perda de ancoragem com maior intensidade no grupo II, porém estatisticamente não significante.

- O grupo I exibiu maior migração radicular para mesial do primeiro molar inferior, alcançando significância estatística.

- Os incisivos inferiores exibiram inclinação coronária para vestibular em ambas as técnicas, todavia apresentando uma maior intensidade no grupo I, mas sem significância estatística.

- O grupo II apresentou menor inclinação radicular dos incisivos inferiores para lingual, embora estatisticamente não significante. 
1 INTRODUÇÃo 


\section{1 - INTRODUÇÃO}

$\mathrm{A}_{\text {é um dos principais fatores para que a mecânica }}$ ortodôntica seja satisfatoriamente empregada.

A busca pela utilização adequada de técnicas de ancoragem iniciou-se com a própria evolução da mecânica ortodôntica, mecânica esta que vem sendo pesquisada e aprimorada desde o início deste século.

ANGLE$^{8}$, em 1907, encontra-se entre os pioneiros que se dedicaram a estas investigações, quando classificou a ancoragem em simples, estacionária e recíproca. Anos mais tarde, introduziu a técnica do Arco de Canto (Edgewise), possibilitando o controle da movimentação dentária nas três dimensões do espaço. Esta técnica foi originalmente idealizada para a correção de más oclusões, segundo seu princípio não extracionista.

Contrariamente, TWEED ${ }^{90}$, considerando a necessidade de exodontias como forma de harmonizar as bases ósseas e os elementos dentários, introduziu expressivas modificações na mecânica da técnica do Arco de Canto. Tornou-se ainda maior a preocupação com a ancoragem, a fim de que os espaços conseguidos fossem corretamente utilizados no posicionamento dos dentes anteriores, resultando num perfil harmonioso.

ANDREWS ${ }^{4}$, em 1976, percebendo que as mecânicas ortodônticas existentes exigiam que fossem realizadas dobras 
semelhantes durante todas as fases do tratamento, introduziu a técnica do Arco Reto (Straight Wire), incorporando aos braquetes as dobras antes realizadas em todos os arcos na técnica do Arco de Canto. Mesmo com a transição de uma técnica para outra, ainda continuou a preocupação com a ancoragem.

Da mesma forma que a ancoragem é tida como preocupante, a própria mecânica ortodôntica, durante a fase de nivelamento, gera limitações que devem ser observadas durante os procedimentos clínicos.

$\mathrm{Na}$ primeira fase do tratamento ortodôntico corretivo com extrações dentárias, deve-se chegar a um alinhamento e nivelamento dos dentes mal posicionados, preparando-os para a colocação do fio retangular na fase subseqüente. É necessária uma abertura de mordida na região anterior para facilitar a movimentação dentária, durante a fase de retração anterior.

Para a obtenção destes desideratos, pode ocorrer notoriamente uma perda de ancoragem dos dentes posteriores e uma inclinação para vestibular dos dentes anteriores que, na maioria dos casos, interferem sobremaneira no sucesso da correção ortodôntica.

Considerando-se a relevância do tema, julga-se oportuno encetar um estudo comparativo entre as técnicas do Arco de Canto Simplificada e a técnica do Arco Reto, no que tange à perda de ancoragem inferior na fase de nivelamento. 


\section{2 - REVISÃO DE LITERATURA}

1 m 1907, $\mathrm{ANGLE}^{8}$ classificou a ancoragem em simples,
estacionária, reciproca, intermaxilar e occipital. A ancoragem simples pressupõe um movimento de inclinação que ocorre quando a resistência é alcançada por meio de uma força localizada em um dente, ou em um grupo de dentes de maior tamanho e de melhor localização. A ancoragem estacionária, por sua vez não deve apresentar movimentação nos dentes de resistência, mas, caso ocorra, deve ser de corpo e em ambos os pontos da aplicação da força. A ancoragem recíproca permite a movimentação dentária em ambos os pontos de aplicação da força. Quando a ancoragem é obtida em dentes do arco antagonista, denomina-se de ancoragem intermaxilar. Finalmente, na ancoragem occipital, a resistência é conseguida por um dispositivo apoiado na parte póstero-superior da cabeça, com elásticos transmitindo a força aos dentes.

Um ano depois, $\mathrm{CASE}^{26}$, preocupado com a perda de ancoragem que ocorria em tratamentos com extrações de prémolares, indicou a bandagem de todos os dentes nos segmentos posteriores e pontos de solda entre as bandas posteriores, como ancoragem estacionária para a retração dos dentes anteriores. 
ANGLE 8 também desenvolveu o Arco Redondo "E", que possuía extremidades rosqueadas e porcas ajustadas nos tubos de secção redonda das bandas dos molares. Ele também idealizou o aparelho de pino e tubo com controle tridimensional dos dentes. Posteriormente, o próximo aparelho desenvolvido por Angle foi o Arco em Cinta, no qual a fixação dos arcos era realizada por meio de pinos, dispensando a utilização de amarrilhos.

Devido aos inconvenientes destes aparelhos, ANGLE $^{9}$ introduziu, em 1928, a técnica do Arco de Canto (Edgewise) que, sem dúvida alguma, foi um dos maiores legados à Ortodontia. Nesta técnica, Angle preconizava a bandagem de todos os dentes e a utilização de braquetes e tubos retangulares $(0,022$ ” X 0,028”). A utilização dos amarrilhos para a fixação dos arcos voltou a ser realizada e como estes arcos possuíam também uma secção retangular $(0,021$ ” X 0,025”), com sua maior dimensão paralela ao plano horizontal, permitiam assim o movimento de corpo dos dentes.

Quatro anos depois, JOHNSON53 projetou um novo aparelho ortodôntico, denominado "twin wire". Este aparelho era composto de dois fios de aço inoxidável com espessura variando de 0,009" a 0,014", mantidos nos tubos por atrito. O arco lingual de 0,036" era utilizado como ancoragem inferior.

Em 1936, TWEED ${ }^{90}$ constatou que a utilização dos princípios básicos da técnica do Arco de Canto não conduzia a 
resultados satisfatórios. Para que o caso não se transformasse em uma biprotrusão, Tweed passou a admitir a possibilidade de extrações dos primeiros pré-molares superiores e inferiores, contrapondo-se aos princípios de Angle.

Criticando a mecânica proposta por Tweed, BRODIE et al. ${ }^{18}$, em 1937, acreditavam que os principios de Angle estavam passando por modificações, resultando em maiores complicações em procedimentos já considerados dificeis. O termo "ancoragem estacionária", relativo à uma ancoragem rígida impossível de ser conseguida na cavidade bucal, foi abolido. Afirmavam que os dentes que não sofriam movimentação constituiam a melhor ancoragem e que a quantidade de resistência a uma determinada força dependia do número de dentes incluídos na ancoragem. Preconizavam também a bandagem do maior número de dentes possiveis para haver controle e estabilidade da unidade de ancoragem, ao se utilizar a mecânica do Arco de Canto.

No mesmo ano, CHUCK $^{27}$ preconizou a utilização dos segundos molares inferiores como ancoragem adicional no arco inferior, por apresentarem raízes volumosas e situarem-se próximos ao tecido ósseo denso da borda anterior do ramo mandibular. Recomendava também a bandagem destes dentes mesmo se estivessem encobertos por tecido mole, indicando assim, a remoção cirúrgica do tecido antes da instalação das bandas. 
No mesmo ano, BRODIE et al. ${ }^{18}$, avaliaram cefalometricamente a efetividade da resistência proporcionada pela ancoragem estacionária inferior, em casos de Classe II, 1a divisão, tratados com elásticos intermaxilares. Observaram que os molares inferiores apresentavam uma tendência acentuada de movimento para mesial, enquanto que os dentes superiores permaneciam estáveis. Concluíram, portanto, que o arco inferior não proporciona uma ancoragem satisfatória quando da utilização de elásticos de Classe II.

Apontando a ancoragem como um grande desafio para a Ortodontia, WRIGHT103 em 1939 contestou o termo "ancoragem estacionária”, em razão da impossibilidade de ser obtida intrabucalmente. Para ele, os dentes não movimentados apresentavam uma maior resistência à força aplicada; resistência esta que poderia ser alterada com a utilização de acessórios rígidos.

Em 1940, GOLDSTEIN; MYER ${ }^{41}$ realizaram um estudo cefalométrico do comportamento dos dentes inferiores, durante o tratamento da Classe II. Eles verificaram que as alterações observadas na dentição decídua assemelhavam-se às da dentadura permanente. Com o crescimento, a erupção dos dentes e a tensão resultante dos elásticos de Classe II, há uma inclinação para mesial dos molares inferiores, resultando em vestibularização dos incisivos inferiores. 
No mesmo ano, DOWNS ${ }^{34}$ afirmou que quando ocorre um alto grau de inclinação axial para distal nos dentes posteriores, observa-se grande mesialização dos ápices radiculares. Para ele, se estivesse indicada uma verticalização de molares, ela deveria ser realizada com cautela, porque o movimento distal da coroa poderia parecer pequeno do ponto de vista clínico, mas que deveria se ter em mente que suas raízes estariam sendo movimentadas em sentido contrário à inclinação axial normal.

Defendendo a necessidade do posicionamento dos dentes em suas inclinações axiais corretas, TWEED ${ }^{91}$, em 1941, afirmou que, somente após a verticalização dos dentes inferiores, em relação a sua base óssea, e a manutenção nessa posição, se poderia utilizar estes dentes como resistência mecânica eficiente à tendência de mesialização dos mesmos, durante a utilização dos elásticos de Classe II. Esta fase do tratamento durava, em média, quatro meses e foi denominada de "preparo de ancoragem".

Ainda em 1941, TWEED ${ }^{92}$ elaborou seu plano geral de tratamento, composto de três fases. A primeira objetivava o preparo de ancoragem no arco inferior, em tratamentos de Classes I, II e biprotrusões. Durante a segunda fase, realizava-se a retração "em massa" dos dentes, para a correção ânteroposterior entre os arcos. Na última fase, detalhava-se o posicionamento dentário, preparando para a fase de contenção. O preparo de ancoragem inferior consistia da movimentação para lingual dos dentes anteriores, conseguida por meio do controle de 
torque, associado à inclinação para distal dos dentes posteriores, realizada por meio da incorporação de degraus distais nos arcos retangulares. Estes procedimentos eram realizados concomitantemente à aplicação de elásticos de Classe III, associados à utilização do aparelho extrabucal.

Para STRANG86, ainda em 1941, a chave para o sucesso de qualquer mecânica ortodôntica dependia de três fatores: a compreensão do mecanismo biológico e suas limitações; os princípios mecânicos envolvidos e a utilização correta da ancoragem. O termo "ancoragem estacionária” apresentava sentido relativo, representando a resistência ao movimento ou às forças ortodônticas. Este mesmo autor aprovou clinicamente o procedimento de preparo de ancoragem preconizado por Tweed, mesmo não se fundamentando corretamente em conceitos biológicos. Não houve dúvidas de que a ancoragem obtida, posicionando-se os dentes numa situação mecanicamente mais vantajosa para se contrapor às forças de deslocamento, apresentava maior estabilidade do que dentes não movimentados.

COLEMAN ${ }^{30}$, em 1943, pesquisando o preparo de ancoragem, verificou que o objetivo principal deste procedimento seria a obtenção de uma ancoragem intrabucal mais eficiente. Coleman concordava que os incisivos inferiores deveriam se encontrar verticalizados sobre o osso basal e os dentes posteriores, inclinados para distal. O preparo de ancoragem no arco inferior deveria ser realizado como uma unidade a fim de 
resistir ao deslocamento anterior dos dentes, resultante da mecânica com elásticos de Classe II.

No mesmo ano, SALZMANN ${ }^{81}$ afirmou que a quantidade de resistência natural à movimentação dentária relaciona-se diretamente com o osso no qual os dentes encontram-se implantados, com a área da superficie radicular dos dentes, com a pressão muscular e com a intercuspidação dentária.

Um ano depois, SHELDEN ${ }^{84}$ salientava que o preparo de ancoragem não deveria ser encarado do mesmo modo em todos os tratamentos. Em vários casos de Classe I e Classe II, os incisivos inferiores encontravam-se próximos de suas posições ideais sobre o osso basal. Enfatizava também a importância da utilização dos segundos molares como ancoragem adicional na técnica do Arco de Canto, modificada por Tweed.

Ainda em 1944, TWEED ${ }^{93}$ reafirmou a necessidade de extrações dos pré-molares para a estabilidade do tratamento, levando em conta a posição correta dos incisivos inferiores em relação ao osso basal.

No mesmo ano, BRODIE ${ }^{19}$, após ter observado os resultados de vários casos tratados, criticou o procedimento do preparo de ancoragem associado às extrações dentárias. Concluiu que havia falhas nos objetivos desta técnica, pois ocorria, na maioria das 
vezes, um maior deslocamento anterior das raízes em comparação com a distalização das coroas.

Já em 1945, TWEED ${ }^{94}$, no intuito de responder as críticas contra sua técnica do preparo de ancoragem, esclareceu que o procedimento se baseava em uma teoria científica de tratamento, e que os resultados poderiam ser comprovados pela grande quantidade de casos tratados com essa mecânica. Tweed afirmava que, para se obter o preparo de ancoragem da melhor forma possivel, os elásticos de Classe III deveriam ser utilizados em conjunto com o aparelho extrabucal e com os degraus distais.

Em 1947, NANCE $^{67}$ concluiu que o comprimento do arco inferior, na dentadura mista, poderia ser aumentado somente em casos com incisivos inclinados para lingual ou com molares inclinados para mesial. As extrações dentárias, portanto, estariam indicadas em boa parte dos casos onde há apinhamento ou protrusão dentária.

KLOEHN ${ }^{57}$, no mesmo ano, enfatizava que o comprimento do arco inferior, bem como o do superior, poderiam ser aumentados. Entretanto, se o aumento acontecesse no arco inferior, certamente ocorreriam problemas quando os dentes inferiores fossem utilizados como ancoragem intermaxilar. Este autor apontou também as vantagens da ancoragem extrabucal para redirecionar o crescimento ósseo em idades precoces. 
No ano seguinte, EPSTEIN ${ }^{35}$ avaliou o efeito da utilização da ancoragem extrabucal no tratamento das más oclusões de Classe II, 1a divisão e observou uma correção da relação molar no sentido ântero-posterior, em razão do crescimento e da colaboração do paciente.

$\mathrm{ROHDE}^{78}$, em 1948, afirmou que o tecido ósseo constitui a verdadeira fonte de ancoragem a qualquer força transmitida aos dentes e quanto maior a quantidade de fibras no ligamento periodontal, maior é a resistência. Relatou ainda que há dois métodos para se utilizar a ancoragem no arco inferior : o arco lingual e a bandagem de todos os dentes. Para Rohde, a melhor unidade de ancoragem são os dentes não movimentados.

Ainda no ano de 1948, COLE ${ }^{29}$ realizou um estudo cefalométrico em vinte e um pacientes tratados pela técnica do Arco de Canto, com extrações dos primeiros pré-molares. Verificou que em 50\% dos casos ocorreu maior movimento para mesial dos molares que movimento distal dos incisivos.

Um ano depois, BUCHNER ${ }^{20}$ preconizava o tratamento ortodôntico precoce antes da erupção dos caninos. Ele acreditava que nesta fase o arco inferior, com dez dentes irrompidos e aptos a serem bandados, oferecia uma excelente ancoragem. Afirmou também que o torque lingual de coroa e as dobras de 2 a ordem, os degraus distais, resultavam no fracasso da ancoragem inferior, 
em vez de proporcionar resistência ao deslocamento desnecessário.

MOYERS; HIGLEY66, em 1949, no intuito de diminuir a necessidade da utilização da ancoragem extrabucal, desenvolveram uma placa estabilizadora para obter uma resistência de dentes e estruturas alveolares, utilizada concomitantemente ao tratamento ortodôntico.

Alicerçado em um estudo cefalométrico sobre a ancoragem, HIGLEY ${ }^{45}$, em 1950, também indicava a utilização de placas estabilizadoras coadjuvantes da ancoragem, pois acreditava que outra fonte de resistência deveria ser empregada, além dos dentes.

KLOEHN ${ }^{58}$, no mesmo ano, avaliando os aspectos fisiológicos do movimento dentário, considerou a ancoragem do tipo intermaxilar como insatisfatória. Como preconizava o tratamento ortodôntico durante a fase de dentadura mista, elegeu o aparelho extrabucal como responsável pelo movimento dentário do tipo ideal. Preconizava que o comprimento do arco inferior deveria ser preservado no tratamento das más oclusões de Classe II.

LEWIS $^{60}$, ainda em 1950, preconizava a utilização de placas removiveis para a verticalização dos caninos superiores, em casos de extração dos primeiros pré-molares. No arco inferior, utilizava molas de secção aberta e para a preservação da ancoragem 
inferior, instituía o uso do aparelho extrabucal, anulando os efeitos nocivos dos elásticos de Classe II.

Em 1951, STRANGE88 afirmava que a própria separação dos dentes para o procedimento de bandagem poderia gerar migrações ou inclinações indesejáveis, interferindo na ancoragem. Salientava ainda que a ação das forças aplicadas por meio dos elásticos intermaxilares, produziam forças que repercutiam diretamente nos dentes e, por meio das fibras periodontais, no processo alveolar. A resultante desta força era transmitida para frente por meio dos contatos proximais dos dentes localizados anteriormente.

No mesmo ano, SANDUSKY JR. ${ }^{82}$ afirmou que inexiste intrabucalmente uma verdadeira forma de ancoragem estacionária. Os dentes servem apenas como unidades de resistência e dependem dos princípios biológicos que regem o periodonto e o tecido ósseo. Preconizou também o uso da placa estabilizadora, que possui uma maior efetividade na produção de uma ancoragem mais estável, quando da utilização dos elásticos intermaxilares.

BULL 22, em 1951, descreveu uma técnica para a retração inicial de caninos e retração anterior, utilizando arcos retangulares seccionados (Bull loop). Ele não preconizava o preparo de ancoragem, afirmando que os dentes não movimentados servem melhor como ancoragem. 
Ainda em 1951, PREZZANO ${ }^{71}$ afirmou que não se pode concluir que um dente que sirva de ancoragem não se movimente quando se aplica uma determinada força. Porém, a perda de ancoragem pode ser administrada de acordo com a filosofia de tratamento a ser adotada, pela relação entre o paciente e o profissional, pela exatidão dos resultados desejados e pela limitação individual de cada caso.

Em 1952, HOLDAWAY ${ }^{47}$ preconizou a angulação de braquetes nos dentes anteriores e posteriores. Nos dentes posteriores era colocada uma angulação disto-oclusal, obtendo assim, o preparo de ancoragem logo na fase de nivelamento. Nos dentes anteriores era colocada uma angulação mésio-incisal, eliminando assim, a necessidade de confecção de dobras artísticas, posicionando estes dentes em suas angulações axiais corretas, logo também na fase de nivelamento.

Dois anos depois, SCHUDY83 já utilizava a técnica do Arco de Canto modificada por Tweed. Trabalhava com o arco lingual inferior, para manter o comprimento do arco durante a retração inicial de caninos. Em casos de Classe II 1a divisão, de difícil tratamento, onde além dos esforços despendidos os objetivos não puderam ser alcançados, Schudy preconizava uma das quatro alternativas : inclinação para lingual dos incisivos superiores, inclinação para vestibular dos incisivos inferiores, correção 
parcial da Classe II, ou uma combinação das três condições anteriores.

Em 1954, após a publicação de sua filosofia de tratamento, TWEED ${ }^{95}$ divulgou sua análise cefalométrica, correlacionando a importância entre os ângulos internos do triângulo, composto pelo plano de Francfort, plano mandibular e pelo longo eixo dos incisivos inferiores.

Ainda em 1954, TWEED ${ }^{95}$ publicou o artigo a respeito do ângulo FMIA, concluindo sua análise cefalométrica. Nos casos de Classe II, 1a divisão, indicava que, durante o preparo de ancoragem no arco inferior, os incisivos deveriam ser posicionados com uma inclinação $5^{\circ}$ a mais para lingual, a fim de resistirem às forças dos elásticos intermaxilares.

$\mathrm{BEGG}^{13}$, no mesmo ano, aproveitando a filosofia do aparelho pino e tubo de Angle, desenvolveu sua técnica utilizando fio redondo 0,018" de aço inoxidável, com têmpera elevada. As propriedades do fio possibilitavam a liberação de forças leves por longos periodos e, além disso, a incorporação de alças, possibilitava a movimentação dentária nos sentidos horizontal e vertical.

Ainda em 1954, STRANG ${ }^{87}$ afirmava que a ancoragem poderia ser conseguida de três modos : o primeiro pela oposição de um grupo de dentes contra um dente individualmente; o 
segundo com a utilização de um aparelho que permitisse um movimento de corpo dos dentes de ancoragem, caso eles apresentassem deslocamento juntamente com um movimento de inclinação dos dentes. Finalmente, o terceiro mecanismo de ancoragem consistia na utilização de elásticos intermaxilares ou de um aparelho extrabucal. Para Strang, vários fatores poderiam resultar na falha do sistema de ancoragem empregado. Um dos principais fatores seria a interferência oclusal de dentes a serem movimentados, que poderia ser solucionada com a utilização de uma placa de mordida.

HERZBERG44, em 1954, afirmava que quando houvesse maior movimentação dentária, menor espaço disponível ou uma grande combinação dos dois fatores, seria necessário lançar mão de uma ancoragem máxima, acentuando-se os degraus distais no arco inferior e aumentando-se o uso de elásticos de Classe III.

Ainda em 1954, OLIVER et al. ${ }^{68}$ preconizavam a técnica "lábio-lingual" que proporcionava uma ancoragem bastante satisfatória. O arco vestibular deveria sempre ser utilizado juntamente com o arco lingual, como reforço de ancoragem e também para maior controle da movimentação dos dentes anteriores.

Em 1955, WILSON ${ }^{102}$ apresentou variações na técnica "lábio-lingual" para o tratamento das más oclusões de Classe II. Utilizava um arco lingual com alças para ajustes que, quando 
bem adaptado aos dentes anteriores, permitia o movimento para distal dos dentes posteriores e, também, a preservação da ancoragem durante a utilização dos elásticos de Classe II.

No mesmo ano, HOPKINS 48 considerou o arco inferior inadequado e extremamente variável, quando utilizado como ancoragem no tratamento das más oclusões de Classe II.

WEBER ${ }^{100}$, em 1956 descreveu algumas alterações na técnica de Johnson, adaptando-a a casos com extrações. A retração de caninos era realizada com arco seccionado e, como ancoragem, utilizava uma combinação de botão palatino e aparelho extrabucal.

Adepto da técnica de Johnson, KANTER ${ }^{55}$, em 1956, preconizou a utilização de forças extrabucais, que reduziriam de 30 a $50 \%$ a intensidade das forças recíprocas dos elásticos de Classe II atuantes no arco inferior. Afirmou que com a utilização constante destes elásticos, ocorre uma rotação e inclinação para mesial dos primeiros molares, podendo haver um deslocamento anterior de todo o arco inferior.

Em 1956, BEGG ${ }^{14}$ descreveu uma técnica de aplicação de forças leves para a movimentação dentária, utilizando fios de aço inoxidável redondos e de pequeno calibre. Todos os tipos de movimento necessários, tais como os de corpo, torque e de inclinação poderiam ser obtidos com a técnica de Begg. Em sua 
técnica não utilizava ancoragem extrabucal, afirmando que apenas as raízes dos primeiros molares oferecem ancoragem suficiente para a retração dos dentes anteriores. Observou que as falhas em se mover os dentes anteriores para trás e a inabilidade de se impedir que os dentes posteriores se movam para frente, durante o tratamento com extrações de pré-molares, não ocorrem devido à ancoragem insuficiente, mas sim à aplicação de uma força excessiva. Begg afirmava que os primeiros molares permanentes eram suficientes como ancoragem durante a fase de retração anterior, quando se utilizam forças leves.

RENFROE73, ainda em 1956, objetivando revisar os princípios e os métodos de ancoragem e questionar a idéia de que apenas a ancoragem extrabucal deve ser considerada estável, idealizou a placa lábio ativa (lip bumper). A função deste aparelho era a de não somente eliminar a pressão do lábio inferior hipertônico sobre os incisivos inferiores, mas também distalizar os primeiros molares inferiores.

Após encetar um estudo cefalométrico em 36 casos antes, durante e depois do preparo de ancoragem inferior, FOGEL ${ }^{36}$, em 1957 , observou que a coroa de quase todos os primeiros molares distalizava durante o preparo de ancoragem e, além disso, com a utilização dos elásticos de Classe II, os molares inferiores inclinavam-se para vestibular. Concluiu também que a inclinação axial dos incisivos inferiores deve ser reduzida para compensar a mesialização resultante da utilização dos elásticos de Classe II. 
No mesmo ano, BUCHNER ${ }^{21}$ discorreu sobre a ancoragem no tratamento das más oclusões de Classe II, 1 a divisão. Afirmou que a utilização de elásticos intermaxilares parecia não alterar a relação dos dentes inferiores com sua base óssea, caso fossem utilizadas forças leves e se ocorresse crescimento suficiente durante o período de tratamento.

Para $\mathrm{BAY}^{12}$, a maneira mais eficiente de se obter uma ancoragem satisfatória no arco inferior, sem risco de rotação ou inclinação, era com a utilização do arco lingual, com dobras soldadas e inseridas em tubos ovais verticais, fixados às bandas dos primeiros molares permanentes e segundos molares decíduos ou segundos pré-molares.

Em 1958, STONER85 considerou que o termo "ancoragem" englobava a utilização da ancoragem existente, o preparo de ancoragem e o reforço de ancoragem. Enfatizou que o procedimento de preparo de ancoragem, apesar de apresentar excelentes resultados clinicamente, contraria os princípios biológicos e fisiológicos. Durante o tratamento, se a ancoragem existente não fosse suficiente, as forças occipitais ou cervicais poderiam ser utilizadas como reforço de ancoragem, assim como um arco lingual soldado ou removivel, ou ainda aparelhos removiveis com molas digitais. 
PARROT JR.69, no mesmo ano, descreveu a técnica do aparelho universal, modificada para casos com extrações. Durante a fase de nivelamento inferior, utilizava-se o arco lingual inferior como ancoragem, sendo removido nas fases de retração de caninos e retração anterior. Com a remoção do arco lingual nestas fases, ocorria rotação e inclinação vestíbulo-lingual nos molares inferiores, que eram reposicionados por meio de um novo arco lingual, ajustado até se tornar passivo, reposicionando corretamente os dentes.

Após realizarem um estudo histológico para verificar as alterações teciduais em macacos, durante a movimentação dentária induzida, HUETTNER; WHITMAN 50 evidenciaram que os movimentos de torque e de inclinação para distal, são os que causam maior dano aos tecidos dentários. Observaram também que a inclinação dos segmentos posteriores para distal, não aumentava a resistência ao deslocamento para mesial, durante a fase de retração anterior.

Em 1959, GUERRERO ${ }^{43}$ apresentou uma técnica para a distalização de molares e pré-molares, utilizando a barra vestibular de Atkinson, com o mínimo comprometimento da ancoragem inferior. Os dentes anteriores eram posicionados por meio da ancoragem cervical. Esta técnica possuía a vantagem de que, se o paciente não colaborasse, não haveria movimentação dentária indesejável, como ocorre em algumas técnicas. 
No mesmo ano, WEIN ${ }^{101}$ avaliou clínica e cefalometricamente 40 casos de Classe II tratados sem extrações, por meio de elásticos intermaxilares, utilizando ao mesmo tempo o arco lingual removível como fonte de ancoragem. Como resultados, observou um aumento médio de $2,5^{\circ}$ na inclinação para vestibular e de $1,15 \mathrm{~mm}$ na protrusão dos dentes anteriores inferiores.

Em 1960, JARABAK ${ }^{52}$ introduziu modificações na técnica de Tweed, na qual o preparo de ancoragem era obtido por meio da utilização de fios redondos e braquetes angulados. Este procedimento propiciava a liberação de forças leves e contínuas, que promoviam uma atividade mais fisiológica durante a movimentação dentária. A utilização do fio retangular não era dispensada; somente era empregado quando houvesse necessidade de controle de torque, durante a retração anterior e nas fases finais do tratamento.

No mesmo ano, HIGLEY ${ }^{46}$ afirmou que, quando se utiliza o aparelho extrabucal, placas estabilizadoras ou o arco lingual, a ancoragem torna-se menos preocupante. A ação da musculatura peribucal possui uma influência significante sobre o tratamento e também sobre a fase de contenção. Quanto à utilização dos elásticos de Classe II, há um deslocamento para anterior dos dentes inferiores, independente do aparelho utilizado, mas principalmente quando se utiliza o arco lingual. 
Ainda em 1960, HOPKINS ${ }^{49}$ asseverava que se um caso necessitasse de ancoragem inferior, o planejamento deveria ser o de preservar a ancoragem o máximo possível. O melhor procedimento seria a bandagem de todos os dentes e a utilização de um arco lingual passivo.

Discorrendo sobre as limitações do tratamento da Classe II, KLOEHN59, em 1961, relatou que se os dentes inferiores não fossem utilizados como ancoragem dos elásticos de Classe II, a ancoragem extrabucal cervical poderia, em certos casos, promover um aumento do arco dentário inferior, corrigindo até apinhamentos e rotações.

Em 1962, BURSTONE23 descreveu a técnica do arco segmentado, idealizado para liberar forças leves e constantes com controle satisfatório da ancoragem. As unidades de ancoragem posterior eram compostas de fios rígidos $(0,215$ ” $\mathrm{X} 0,28$ ”), que uniam os dentes de ancoragem de cada hemi-arco por meio de uma barra palatina. Para a retração dos dentes anteriores eram utilizadas molas de calibre menor, entre os segmentos posterior e anterior, e que liberavam forças fisiologicamente mais leves.

Por meio de estudo histológico em humanos, REITAN ${ }^{72}$, em 1962, provou que, após oito dias do procedimento de preparo de ancoragem, havia a calcificação do tecido osteóide, tornando-o mais suscetivel de sofrer reabsorção. 
Em um estudo cefalométrico de 30 casos tratados pela técnica do Arco de Canto, MAZZEI63, em 1962, avaliou os efeitos dos elásticos de Classe II e de Classe III, durante o tratamento de Classes I e II, com extrações. Concluiu que a preservação da ancoragem é, na verdade, um processo contínuo de perda gradativa de ancoragem.

Em 1963, DENHOLTZ33 reintroduziu a placa lábio ativa, aparelho que utiliza a pressão muscular para facilitar a movimentação dentária. Este aparelho pode ser utilizado tanto no arco superior quanto no inferior, sendo indicado para a distalização de molares, como ancoragem em casos com extrações, impedindo a mesialização dos molares e como reforço de ancoragem.

Questionando a necessidade da utilização de elásticos de Classe II na maioria dos casos ortodônticos, FREEMAN38 em 1963 afirmou que a distalização do arco superior poderia ser obtida, mais satisfatoriamente, por meio de força extrabucal.

No mesmo ano, KESLING 56 enumerou 35 prováveis causas da perda de ancoragem, durante os dois primeiros estágios da técnica de Begg. A maioria das causas relacionava-se ou à falta de habilidade na utilização da técnica ou à ausência de colaboração dos pacientes. 
Ainda em 1963, FOGEL; MAGILL 37 descreveram um método combinando a técnica de Begg com a Arco de Canto. A retração inicial de caninos poderia ser realizada por meio de placas de mordida, molas ou arcos segmentados com alças. Esse movimento de inclinação dos caninos, em direção aos espaços das extrações, resultava numa perda de ancoragem menor comparado ao movimento de corpo desses mesmos dentes. Em casos críticos, durante a retração anterior, utilizava-se, como reforço de ancoragem, o botão de Nance e elásticos de Classe III.

DAGUE ${ }^{32}$, em 1964, avaliou cefalometricamente a estabilidade da ancoragem inferior, visualizando a alteração na posição dos primeiros molares permanentes. Utilizou dois grupos de pacientes da mesma faixa etária, com más oclusões semelhantes, durante o mesmo período. O primeiro grupo foi tratado pela técnica "twin wire". Avaliou, também, num grupo controle sem tratamento, as alterações na posição dos molares relacionadas apenas ao crescimento. Observou nos dois grupos um movimento dos molares inferiores para cima e para frente, sem inclinação no seu longo eixo. Houve um aumento significante na direção ântero-superior dos molares no grupo que recebeu tratamento.

Avaliando o preparo de ancoragem em casos corrigidos com extrações de quatro pré-molares, VIETH ${ }^{98}$, em 1964, observou que os elásticos de Classe III, associados às dobras de segunda ordem, não são efetivos para evitar o movimento para mesial da 
raiz dos molares. Verificou que, após este procedimento, ocorreu um milímetro de distalização da coroa e, 2,7 milímetros de mesialização da raiz em casos bandados até os primeiros molares. Para suavizar esta perda de ancoragem, recomendou a bandagem dos segundos molares inferiores.

TWEED ${ }^{96}$, em 1966, consolidou as regras relacionadas ao preparo de ancoragem. Ele afirmou que a quantidade do preparo de ancoragem deveria variar de acordo com determinados fatores, tais como a discrepância de modelo, o ângulo ANB e a estética facial. Contestou as pesquisas que afirmavam que o dente não movimentado representa a melhor unidade de resistência e que o simples ato da separação e da bandagem já alteraria a posição inicial dos dentes.

No mesmo ano, ALLEN ${ }^{2}$ criticou o uso indiscriminado dos elásticos intermaxilares, mesmo sendo parte indispensável da mecânica do Arco duplo de Johnson (twin wire). Recomendava a utilização da placa lábio ativa como auxiliar no tratamento para evitar a perda de ancoragem inferior e para remover a pressão do lábio inferior sobre a face palatina dos incisivos superiores.

Combinando a mecânica de deslizamento com os arcos laminados, CAREY ${ }^{25}$, em 1966, descreveu uma técnica com fios leves. Obtinha-se uma inclinação para distal dos dentes posteriores para realizar a retração inicial de caninos e dos incisivos, mediante a utilização de forças leves e independentes. 
Empregava como ancoragem inferior um arco lingual de secção retangular (0,016” X 0,022”), com alças e helicóides na região de pré-molares, que serviam de encaixe para os elásticos de Classe III e, como reforço de ancoragem superior, uma placa estabilizadora.

SUBTELNY; SAKUDA89 em 1966, pesquisando as telerradiografias de 25 pacientes que utilizaram placa lábio ativa, observaram que a distalização dos molares inferiores ocorreu em 22 pacientes (88\%) e a vestibularização dos incisivos inferiores em 11 casos (44\%). Concluíram que a atividade funcional do lábio inferior deve ser utilizada durante a mecânica ortodôntica, sendo a placa lábio ativa o aparelho ideal para a obtenção de espaço no arco inferior.

Em 1967, GUAY; BAKER ${ }^{42}$ realizaram um estudo cefalométrico com 40 pacientes tratados ortodonticamente com extrações de quatro pré-molares, utilizando ancoragem máxima. Observaram uma perda de ancoragem menor quando foram utilizados aparelhos auxiliares para ancoragem, em comparação ao emprego de forças direcionais.

No ano seguinte, WALKER ${ }^{99}$ descreveu uma técnica indicada para casos com extrações de quatro pré-molares com ancoragem máxima, utilizando cursores nos arcos superior e inferior. Nos ganchos dos cursores superiores adaptava-se o aparelho extrabucal com apoio occipital, enquanto que os ganchos dos 
cursores inferiores serviam de encaixe para os elásticos de Classe III. Com esta técnica obtinha-se a retração de caninos sem perda de ancoragem ou até com uma certa distalização do segmento posterior, quando desejada.

Em 1969, ACKERMAN et al. ${ }^{1}$ introduziram uma modificação na técnica do Arco de Canto, utilizando a força extrabucal sobre os dentes anteriores superiores e inferiores, a fim de retraí-los e não simplesmente, como reforço de ancoragem. A principal vantagem seria a de que, se o paciente não colaborasse com o uso do aparelho extrabucal, ocorreria somente um aumento no tempo de tratamento e não, uma perda de ancoragem.

PAULSON; SPEIDEL; ISAACSON70, em 1970, pesquisaram a perda de ancoragem superior durante a fase de retração dos caninos por meio de estudo laminográfico. A amostra consistiu de seis pacientes com má oclusão de Classe I, tratados com extração dos quatro primeiros pré-molares. Para realizar a retração de caninos foram utilizados elásticos de látex entre os caninos e os molares, que liberavam uma força entre 50 e 75 gramas. A ancoragem superior foi obtida com uma barra palatina $(0,036$ ”) e com o uso noturno do aparelho extrabucal cervical. Com a sobreposição dos traçados das laminografias pôde-se observar a retração de caninos que foi em média de 3,9 milímetros. Adicionalmente, contatou-se a ausência completa de movimento para mesial dos primeiros molares superiores durante esta fase. 
No mesmo ano, MERRIFIELD; CROSS65 divulgaram sua técnica de tratamento com forças direcionais, na qual preconizavam o preparo de ancoragem inferior seqüencial 10-2. Este procedimento baseia-se na utilização de dez dentes para o posicionamento de outros dois, em casos com preparo de ancoragem. Utiliza-se também o aparelho extrabucal de tração alta, apoiado na região anterior, que impede a inclinação do plano oclusal e a vestíbulo-versão dos dentes anteriores.

Um ano depois, GIANELLY40 descreveu um método de tratamento para minimizar a perda de ancoragem inferior, estabilizando a posição do molar inferior. Em sua técnica, ele preconizava o aparelho Arco de Canto sem a bandagem dos segundos pré-molares superiores, onde incorpora uma dobra distal com a finalidade de estabilizar a posição do molar. O aparelho extrabucal é utilizado no arco inferior durante o uso dos elásticos de Classe II.

No ano de 1972, BERGERSEN ${ }^{16}$ avaliou cefalometricamente os efeitos da placa lábio ativa na distalização dos molares inferiores, vestibularização dos incisivos e também durante o uso dos elásticos de Classe II. Os resultados demonstraram que o movimento para distal dos primeiros molares inferiores e a vestibularização dos incisivos inferiores ocorreram em 95\% dos casos. Ao final da fase de nivelamento, a distalização dos molares inferiores foi, em média, de um milimetro. Observou também que 
durante a utilização dos elásticos de Classe II, a placa lábio ativa preveniu a mesialização dos molares inferiores em $67 \%$ dos casos.

Avaliando cefalometricamente a perda de ancoragem entre as técnicas Arco de Canto e a de Begg, BAKER; GUAY; PETERSON ${ }^{11}$ em 1972, observaram a retração maior dos incisivos superiores com a técnica de Begg, porém, não houve diferença significativa na retração dos incisivos inferiores. Em relação à perda de ancoragem, ela foi maior nos casos tratados pela técnica de Begg do que a verificada pela técnica do Arco de Canto.

Em 1972, ANDREWS ${ }^{3}$ realizou uma pesquisa alicerçada na avaliação de 120 modelos de gesso de indivíduos com oclusão normal e que não tinham se submetido a tratamento ortodôntico. Estes modelos foram selecionados por ortodontistas, clínicos gerais e estudantes de Odontologia de um total de 1.150 modelos. Observou que seis aspectos característicos eram freqüentes na maioria dos casos, envolvendo a relação molar, a angulação e a inclinação coronárias, a ausência de rotações e de diastemas e a presença de curva de Spee planificada. Estas seis características significantes foram denominadas de "As seis chaves da oclusão normal" e passaram a constituir os objetivos do tratamento em mais de $90 \%$ dos pacientes tratados por ortodontistas norteamericanos.

No ano seguinte, MARINHO ${ }^{61}$ comparou cefalometricamente os resultados de tratamentos realizados com o técnica de Tweed 
em relação àqueles obtidos empregando-se a técnica preconizada por Holdaway, com braquetes angulados. Constatou resultados semelhantes em ambos os casos, porém ponderou que a técnica com braquetes angulados demanda menos tempo, pois elimina a fase de preparo de ancoragem. Verificou ainda que não houve diferença estatisticamente significante entre a perda de ancoragem comparando-se as duas técnicas.

Utilizando um modelo fotoelástico, CAPUTO; CHACONAS; HAYASHI $^{24}$, em 1974, visualizaram as forças ortodônticas durante a retração de caninos por meio de vários tipos de molas. Observaram que quando há uma combinação adequada do efeito "gable" com angulação de 45 a $60^{\circ}$ com uma intensidade de força inferior a $300 \mathrm{~g}$, pode-se conseguir o movimento de corpo durante a retração de caninos. Porém, se a força for excessiva, independente da angulação do efeito "gable", haverá o movimento de inclinação juntamente com perda de ancoragem.

Em 1976, RICKETTS 74,75 introduziu a Técnica Bioprogressiva, preconizando a ancoragem do molar inferior no osso cortical que, por ser mais compacto e menos vascularizado, não se reabsorve facilmente. Utilizava para este procedimento o arco base inferior, no qual incorporava torque vestibular de raiz nos molares, enquanto produzia a expansão ao nível de coroa destes dentes. Para aumentar ainda mais a ancoragem, o arco base possuía um ângulo caudal que produzia uma inclinação distal dos molares inferiores. Afirmava que os molares inferiores 
posicionados desta forma, resistiriam às forças dos elásticos intermaxilares e às forças de mesialização provenientes das alças de retração dos dentes anteriores. O arco base ou arco de utilidade, como também é conhecido, apoiava-se nos incisivos, resultando na intrusão destes dentes, sem que ocorresse a vestibularização de suas coroas.

Após ter estabelecido as seis chaves para a oclusão normal, ANDREWS ${ }^{4,5}$ desenvolveu, em 1976, um novo aparelho, chamado por ele de "Aparelho Edgewise Sofisticado". Cada braquete era produzido para um tipo específico de dente. As ranhuras eram pré-anguladas, conforme a inclinação mesiodistal de cada dente. As bases dos braquetes eram inclinadas de acordo com a anatomia de cada dente. A distância da base da ranhura até a base do braquete respeitava a posição de cada dente. Essas características foram incorporadas aos braquetes, com o objetivo de incluir as dobras de 1ạ, 2a e e 3a ordens, antes realizadas em cada arco durante o tratamento. Por não necessitar de dobras nos arcos, essa técnica, que utilizava braquetes pré ajustados foi denominada de "Arco Reto" (Straight Wire).

No ano seguinte, RIZZATTO ${ }^{76}$ avaliou cefalometricamente a perda de ancoragem inferior na técnica do Arco de Canto e comparou os casos bandados até os primeiros molares com os bandados até os segundos molares, não encontrando diferenças significativas. $\mathrm{Na}$ região coronária, os casos bandados até os primeiros molares perderam mais ancoragem do que os bandados 
até os segundos molares. Além disto, no que tange à região radicular, os casos bandados até os segundos molares perderam mais ancoragem do que os bandados até os primeiros molares.

Em uma pesquisa por meio de implantes metálicos, MARTINS; INTERLANDI; ALMEIDA ${ }^{62}$, em 1978, avaliaram o comportamento do preparo de ancoragem preconizado por Tweed em dez pacientes com Classe II, 1a divisão, que necessitavam de extrações dos quatro primeiros pré-molares. Em todos os pacientes o preparo de ancoragem foi realizado nos segundos prémolares e nos primeiros molares, apenas no lado direito, enquanto que o lado esquerdo serviu como controle. Evidenciaram que os dentes que receberam o preparo de ancoragem apresentaram uma tendência de movimento para mesial maior ou igual ao grupo controle.

Em 1982, FREITAS ${ }^{39}$ realizou uma avaliação cefalométrica do comportamento da ancoragem inferior, durante todas as fases do tratamento ortodôntico corretivo, empregando a técnica do Arco de Canto com preparo de ancoragem, em pacientes que utilizaram a placa lábio ativa associada aos elásticos de Classe III, acoplados ao aparelho extrabucal no arco superior. Em seguida, comparou estes resultados com os dados obtidos por MARINHO61, em 1973, que analisou a técnica de preparo de ancoragem com braquetes angulados. Concluiu que, no final da fase de nivelamento, as coroas dos molares inferiores inclinaram-se para distal, e enquanto as suas raízes inclinaram-se para mesial. Os 
incisivos mantiveram sua posição inicial na primeira técnica, contudo inclinaram-se para lingual na segunda técnica. No final da fase de retração anterior ocorreu perda de ancoragem em ambas as técnicas, com maior evidência ao nível radicular. Nesta mesma fase, os incisivos exibiram a tendência ao movimento de corpo na primeira técnica e, ao movimento de inclinação na segunda. Até o término do tratamento, ocorreu pouca movimentação dos incisivos e dos molares em ambas as técnicas. No contexto geral, as duas técnicas apresentaram resultados finais semelhantes.

Seis anos depois, JOHNSTON JR.; LIN; PENG54 avaliaram cefalometricamente 100 pacientes com Classe II, 1a divisão, tratados com extrações de quatro pré-molares. Foi empregada a técnica do Arco de Canto, sendo que 34 casos não receberam preparo de ancoragem, 41 foram tratados com preparo de ancoragem convencional e 25 com o sistema de ancoragem 10-2. Observaram que os casos tratados com o sistema 10-2 apresentaram uma maior inclinação para distal dos molares inferiores. Porém, analisando-se globalmente, não ocorreram diferenças significativas entre as médias das três amostras pesquisadas.

Em 1989, CIPRIANO; VIGORITO; RINO NETO28 avaliaram cefalometricamente o comportamento da ancoragem inferior durante as fases de nivelamento e retração anterior, comparando a angulação de braquetes de 3 e 5 graus. A amostra constituiu-se 
de 27 pacientes tratados pela técnica do Arco de Canto com extrações dos quatro primeiros pré-molares. Observaram que no grupo com angulação de $3^{\circ}$, os primeiros molares inferiores mantiveram sua posição coronária, mas exibiram mesialização das raízes nas fases pesquisadas. Já no grupo com angulação de $5^{\circ}$, os primeiros molares inferiores permaneceram estáveis durante a fase de nivelamento; entretanto, na fase de retração anterior, ocorreu mesialização significativa de suas coroas. Ao nivel apical, observou-se mesialização em ambas as fases.

ROBINSON ${ }^{77}$, no mesmo ano, avaliou os arcos inferiores de 57 casos com extrações dos primeiros pré-molares, durante a fase de nivelamento no tratamento com a técnica do Arco Reto. Aproximadamente metade dos casos foi tratado com amarrilhos conjugados nos segmentos posteriores, enquanto que a outra metade foi tratada sem conjugar os segmentos posteriores. Observou que os molares inferiores se movimentaram para mesial cerca de 1,76 $\mathrm{mm}$ nos casos onde se utilizaram amarrilhos conjugados e 1,53 mm quando estes não foram utilizados. Os incisivos inferiores inclinaram-se $1 \mathrm{~mm}$ para lingual, em média, quando se utilizaram os amarrilhos, porém inclinaram-se 1,47 $\mathrm{mm}$ para vestibular quando não se efetuou a conjugação dos segmentos posteriores. Concluiu que apesar dos molares mesializarem um pouco mais quando se utilizam os amarrilhos conjugados nos segmentos posteriores, este dispositivo apresenta controle de ancoragem adequado pois previne que os incisivos inclinem para vestibular. 
Em 1995, VIAZIS ${ }^{97}$ desenvolveu a Terapia Bioeficiente, técnica que utiliza fios superelásticos e braquetes pré ajustados com conformação triangular e versátil. O objetivo principal desta técnica é produzir forças suaves e reduzir o tempo dispendido na fase inicial do tratamento, restando mais tempo para a finalização do caso. 
3 PROPOSIÇÃO 


\section{3 - PROPOSIÇÃO}

urante o tratamento ortodôntico, em inúmeros casos
almeja-se a preservação da ancoragem nos dentes posteriores, assegurando maior disponibilidade de espaço para as fases de alinhamento e retração anterior.

Após o levantamento da literatura, tendo como objetivo trazer alguma contribuição ao estudo da ancoragem, propusemonos a desenvolver esta pesquisa com o objetivo de comparar cefalometricamente a perda de ancoragem inferior durante a fase de nivelamento nas técnicas do Arco de Canto Simplificada (Standard Edgewise) em relação à técnica do Arco Reto (Straight Wire), no que diz respeito ao posicionamento :

3.1 - Da coroa do primeiro molar inferior;

3.2 - Das raízes do primeiro molar inferior;

3.3 - Das coroas dos incisivos inferiores e

3.4 - Das raízes dos incisivos inferiores. 
4 MATERIAL E MÉTODOS 


\section{4 - MATERIAL E MÉTODOS}

\section{1 - Material}

A amostra desta pesquisa englobou 92 telerradiografias 1 em norma lateral, de 46 pacientes de ambos os sexos tratados nos Cursos de Pós-graduação em Ortodontia, da Faculdade de Odontologia de Bauru da Universidade de São Paulo.

A seleção da amostra fundamentou-se nos seguintes critérios :

- semelhança quanto ao grau de apinhamento inferior,

- presença de curva de Spee,

- plano de tratamento com exodontias dos primeiros pré-molares inferiores e

- boa colaboração dos pacientes no que tange à utilização dos recursos de ancoragem.

Com fins comparativos, a amostra foi subdividida em dois grupos, de acordo com a técnica empregada para a correção da má oclusão : 
- Grupo I - Constituído de 54 telerradiografias de 27 pacientes tratados ortodonticamente pela Técnica do Arco de Canto Simplificada.

- Grupo II - Constituído de 38 telerradiografias de 19 pacientes tratados ortodonticamente pela Técnica do Arco Reto.

A técnica do Arco de Canto Simplificada (Fig. 1) foi utilizada com acessórios possuindo canaleta retangular de 0,022" X 0,028 "*.

$\mathrm{Na}$ técnica do Arco Reto (Fig. 2) foram empregados os acessórios Sinterline Plus ${ }^{\circledR * *}$, prescritos por $\mathrm{ROTH}^{79}$, com secção retangular 0,022" X 0,028" e com torques, angulações e offset distais conforme as tabelas 1 e 2 .

Os pacientes do Grupo I apresentavam idade média de 12 anos e 7 meses e os do Grupo II, 12 anos e 9 meses. Todos os pacientes receberam tratamento durante o período de 1995 a 1997, sendo que o tempo de tratamento foi em média de 1 ano e 11 meses para o Grupo I e 1 ano e 9 meses, para o Grupo II. A média da discrepância de modelo foi de $6,10 \mathrm{~mm}$ para ambos os grupos.

Para cada grupo foram tomadas as telerradiografias em norma lateral iniciais, antes dos pacientes receberem qualquer intervenção ortodôntica corretiva, e ao final da fase de nivelamento superior e inferior, antes do início da fase de retração do segmento anterior.

* Morelli

** Abzil-Lancer 
TABELA 1 - Prescrições dos braquetes Sinterline Plus ${ }^{\circledR}$ preconizadas por $\mathrm{ROTH}^{79}$

\begin{tabular}{|c|c|c|}
\hline & Torque & Angulação \\
\hline Incisivos Centrais Superiores & $12^{\circ}$ & $5^{\circ}$ \\
\hline Incisivos Laterais Superiores & $8^{\circ}$ & $9^{\circ}$ \\
\hline Caninos Superiores & $0^{\circ}$ & $11^{\circ}$ \\
\hline 2 os Pré Molares Superiores & $-7^{\circ}$ & $0^{\circ}$ \\
\hline Incisivos Inferiores & $0^{\circ}$ & $0^{\circ}$ \\
\hline Caninos Inferiores & $-11^{\circ}$ & $5^{\circ}$ \\
\hline $2 \stackrel{\text { os }}{\text { Pré Molares Inferiores }}$ & $-22^{\circ}$ & $0^{\circ}$ \\
\hline
\end{tabular}

TABELA 2 - Prescrições dos tubos Sinterline Plus ${ }^{\circledR}$ preconizadas por ROTH $^{79}$

\begin{tabular}{l|c|c}
\hline & Torque & Offset Distal \\
\hline $1^{\text {os }}$ Molares Superiores & $-10^{\circ}$ & $10^{\circ}$ \\
\hline $2^{\underline{\text { os }}}$ Molares Superiores & $-10^{\circ}$ & $10^{\circ}$ \\
\hline $1^{\text {os }}$ Molares Inferiores & & $5^{\circ}$ \\
\hline $2^{\text {os }}$ Molares Inferiores & $-25^{\circ}$ & $5^{\circ}$ \\
\hline
\end{tabular}




\subsection{1 - Descrição da ancoragem utilizada nas técnicas arco de canto simplificada e arco reto}

$\mathrm{Na}$ figura 3, pode-se observar um exemplo da ancoragem utilizada nos tratamentos ortodônticos corretivos da Faculdade de Odontologia de Bauru. Esta ancoragem envolve a instalação do aparelho extrabucal (AEB) no arco superior e da placa lábio ativa (PLA) no arco inferior. Ambos os aparelhos são adaptados aos tubos, soldados às bandas dos primeiros molares. Para aumentar a efetividade da ancoragem, utilizam-se elásticos de Classe III de $5 / 16$ ", colocados nos ganchos pré fabricados ou em recortes na porção acrílica da PLA, estendendo-se até os ganchos localizados nos acessórios dos molares superiores. 


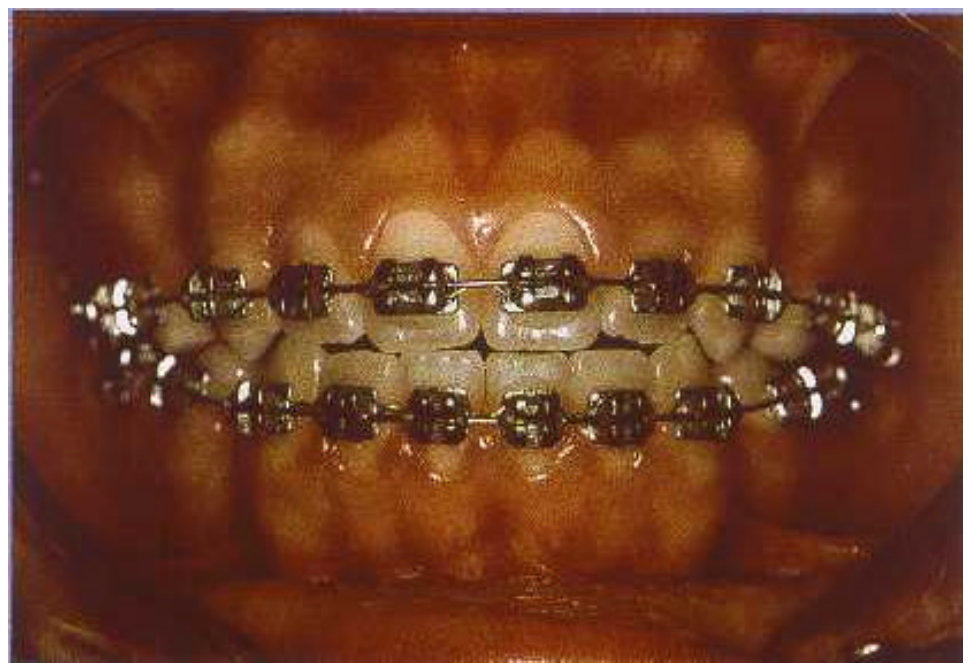

FIGURA 1 - Exemplo Ilustrativo da Técnica do Arco de Canto

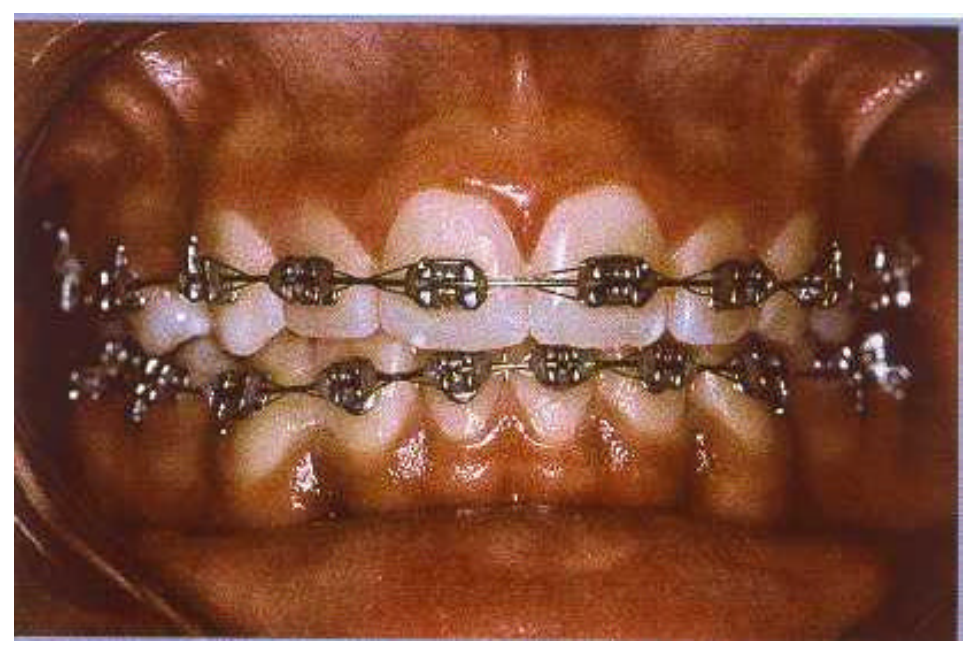

FIGURA 2 - Exemplo Ilustrativo da Técnica do Arco Reto 


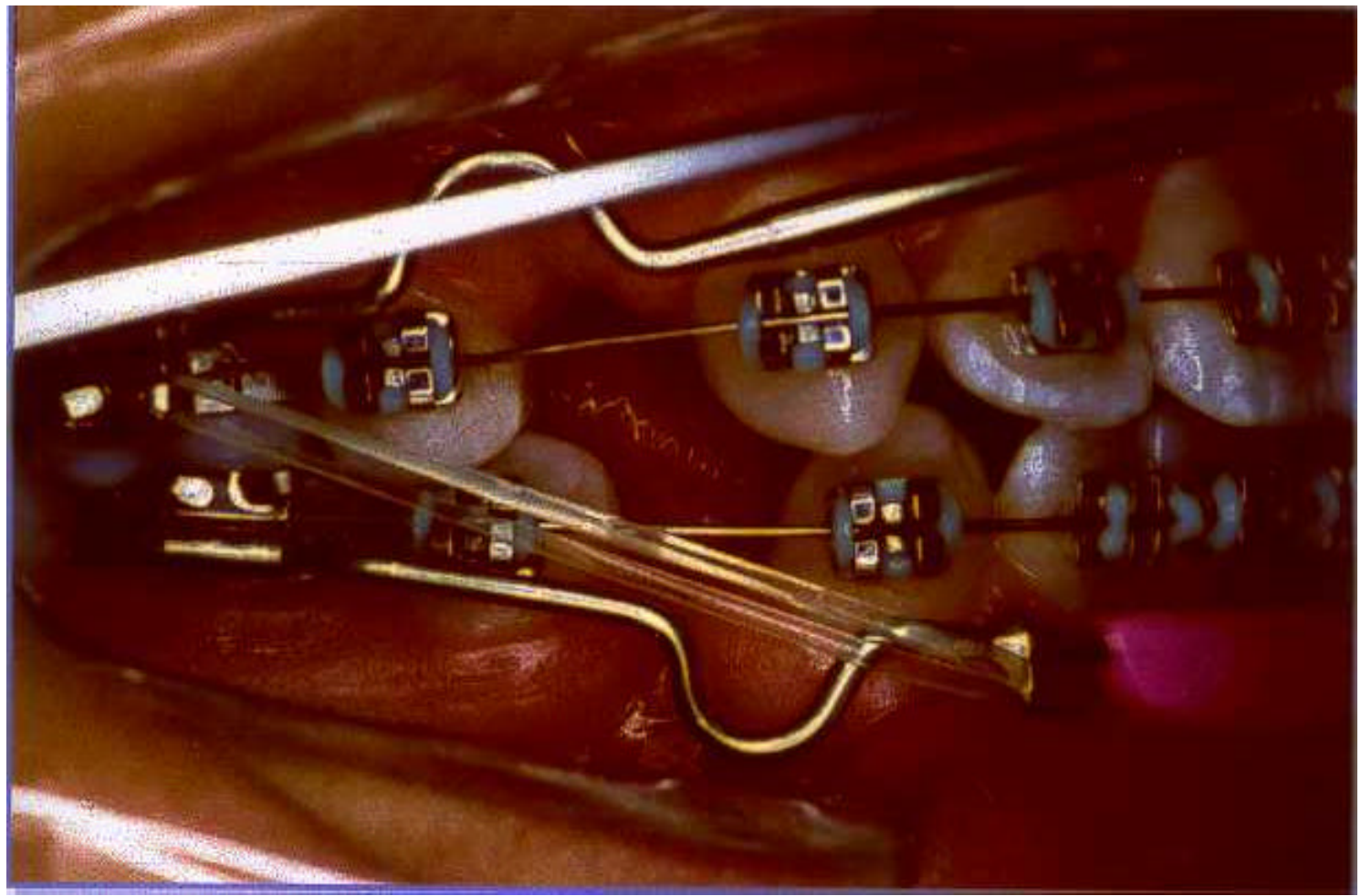

FIGURA 3 - Sistema de ancoragem utilizado nas técnicas do Arco de Canto Simplificada e Arco Reto, composto por aparelho extrabucal, placa lábio ativa e elástico de Classe III 5/16" 


\section{2 - Método}

\subsection{1 - Método Radiográfico}

Para a obtenção das telerradiografias em norma lateral foi utilizado um aparelho de raios X da marca Rotograph Plus ${ }^{\circledR}$, de $80 \mathrm{kVp}$ e $10 \mathrm{~mA}$, com cefalostato, chassi porta-filmes de tamanho 20 X 25 cm, com ecrans intensificadores do tipo Lanex Regular ${ }^{\circledR}$ da Kodak, filmes radiográficos "T-Mat ${ }^{\circledR "}$ da Kodak tamanho $20 \mathrm{X}$ $25 \mathrm{~cm}$, filtro de cobre embutido no colimador para a evidenciação do contorno do perfil mole e avental de borracha plumbifera para a proteção do paciente.

$\mathrm{O}$ aparelho de raios $\mathrm{X}$ foi regulado para $80 \mathrm{kVp}$ e $10 \mathrm{~mA}$, e o tempo médio de exposição utilizado foi de 0,60 segundo, variando de acordo com a estrutura física de cada paciente.

O posicionamento para a tomada radiográfica foi obtido com o paciente em pé, adaptando a altura do aparelho para cada paciente, até que se obtivesse um posicionamento correto das olivas auriculares introduzidas nos meatos auditivos externos, exercendo leve pressão, permitindo assim a padronização das tomadas radiográficas.

Cada paciente foi posicionado com o plano horizontal de Francfort paralelo ao solo, com os dentes em máxima intercuspidação habitual. A distância foco-filme foi de $1,685 \mathrm{~m}$, a mesma padronizada por BROADBENT ${ }^{17}$. O chassi com o filme foi colocado no porta-chassi do cefalostato, do lado esquerdo da face 
do paciente. O feixe de raios X central incidiu perpendicularmente às olivas auriculares, resultando assim, imagens radiopacas concêntricas.

Após a tomada radiográfica, as telerradiografias foram identificadas com o nome, a idade, a data e a fase de tratamento que o paciente se encontrava, início de tratamento ou final de nivelamento.

O processamento radiográfico foi realizado por meio da processadora automática "Cronex Processor T- $4^{\circledR "}$ da Du Pont, à temperatura média de $34^{\circ} \mathrm{C}$.

\subsection{2 - Método Cefalométrico}

Para a execução dos procedimentos pertinentes ao método cefalométrico, foram empregados os seguintes materiais :

- negatoscópio,

- folha de papel acetato (“Ultraphan"),

- fita adesiva,

- lapiseira com grafite 0,3 mm tipo "F",

- régua milimetrada com graduação de 0,5 mm e

- esquadro.

Sobre cada telerradiografia foi adaptada uma folha de papel acetato "Ultraphan", transparente de tamanho 17,5 X 17,5 cm e 
com espessura de $0,07 \mathrm{~mm}$, mantida em posição com fita adesiva. Com o auxílio da lapiseira foi realizado o traçado do das estruturas anátomo-radiológicas de interesse sobre um negatoscópio com máscara de cartolina preta, em sala escurecida. Cada cefalograma foi conferido por um segundo examinador, para se obter precisão na demarcação dos pontos, linhas e planos cefalométricos.

Para fins descritivos, o traçado cefalométrico específico, para determinação da movimentação dos dentes de ancoragem e dos incisivos, foi dividido em :

- Desenho anatômico

- Pontos cefalométricos

- Linhas e planos cefalométricos

- Grandezas lineares

\subsubsection{1 - Desenho anatômico}

O desenho anatômico constituiu-se de detalhes que permitissem o traçado das estruturas de orientação e uma visualização clara e precisa dos contornos das estruturas pesquisadas. Os pontos cefalométricos utilizados situaram-se somente na mandíbula, favorecendo as sobreposições dos traçados e minimizando a interferência de características peculiares das estruturas em crescimento. 
Mandíbula - Na sínfise mentoniana foram traçados os contornos externos das corticais vestibular e lingual e da borda inferior do mento. As bordas inferiores do corpo e posteriores do ramo mandibular foram traçadas em uma ou duas linhas, segundo a ausência ou a presença de imagem dupla.

Dentes incisivos - Foram traçadas as médias dos contornos das coroas e das raízes dos incisivos centrais inferiores.

Dentes molares - Foram traçados os contornos das imagens da coroa e da raiz dos primeiros molares inferiores. Quando da presença de imagem dupla, foi traçado o contorno médio das duas imagens.

\subsubsection{2 - Pontos cefalométricos}

$\mathrm{Na}$ figura 4 encontra-se exemplificado o cefalograma específico utilizado nesta pesquisa, composto do traçado anatômico das estruturas dentoesqueléticas e a demarcação dos seguintes pontos cefalométricos :

- Ponto CM - Determinado pela média dos pontos mais convexos da face mesial das coroas dos primeiros molares inferiores, direito e esquerdo.

- Ponto RM - Situado no ápice, no ponto central do traçado da raiz mesial do primeiro molar inferior. 
- Ponto CI - Localizado no centro da borda incisal da coroa do incisivo inferior.

- Ponto RI - Localizado no ponto central do ápice da raiz do incisivo inferior.

- Ponto Go (Gônio) - Localizado no ponto de intersecção da bissetriz do ângulo formado pelo plano mandibular com a borda posterior do ramo mandibular. A técnica de traçado deste ponto, segundo INTERLANDI ${ }^{51}$ consiste em se colocar a régua tangente à borda posterior do ramo mandibular, marcando-se o ponto onde o traçado se afasta da régua para a direita. A seguir, tangenciando a régua às linhas inferiores do plano mandibular, marca-se, da mesma forma, o ponto onde o traçado se afasta da régua para cima. Na distância média, o ângulo formado entre os dois pontos demarcados, encontra-se o ponto Gônio. Quando há imagem dupla, faz-se a localização do ponto em ambas as linhas e escolhe-se um ponto intermediário entre os pontos assim obtidos.

- Ponto Me (Mentoniano) - Localizado no limite mais inferior da curva da sínfise, no ponto onde o contorno externo das imagens corticais vestibular e lingual se encontram. Geralmente a linha inferior do corpo da mandíbula termina neste limite. 


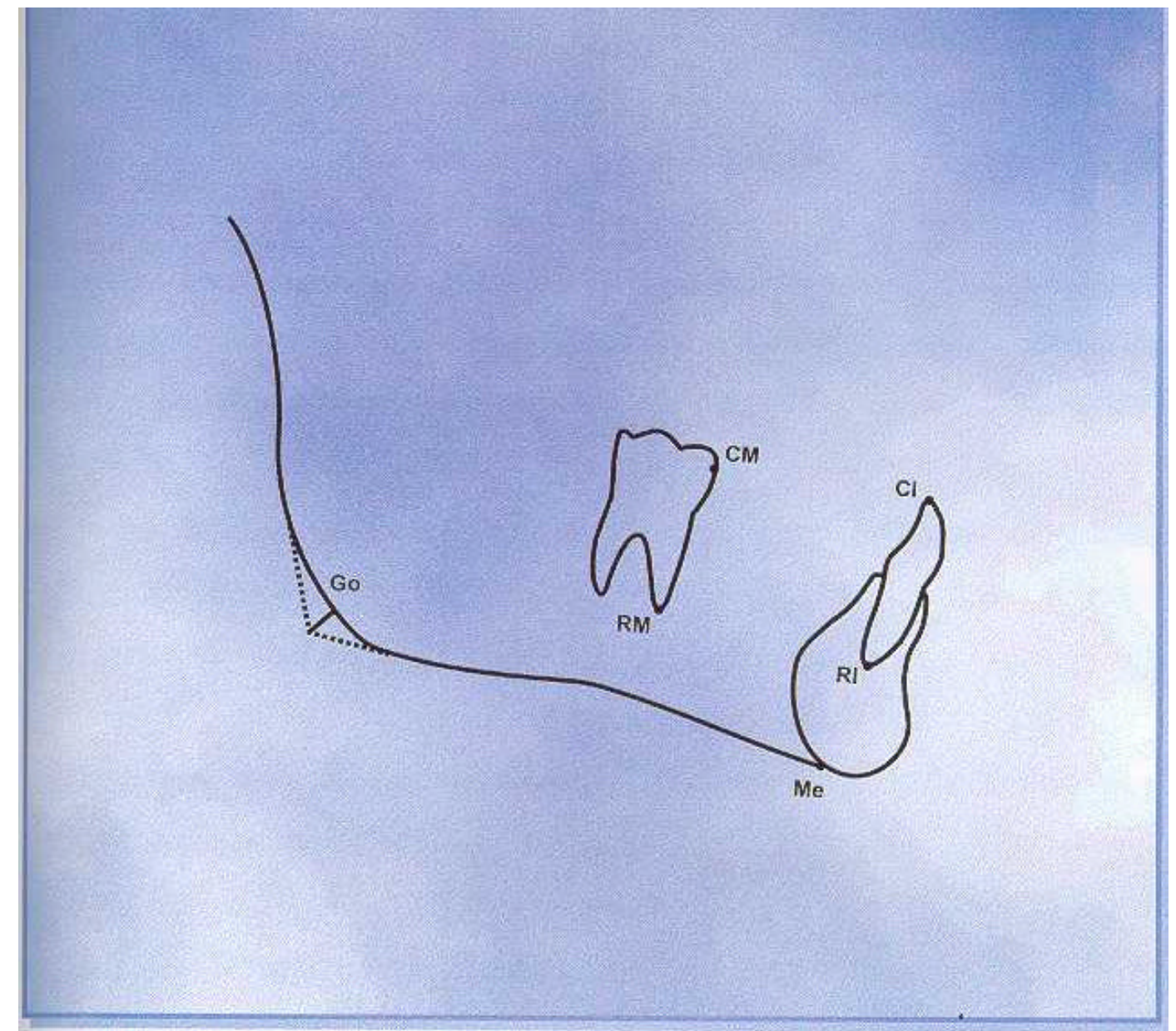

FIGURA 4 - Pontos cefalométricos 


\subsubsection{3 - Linha e plano cefalométricos}

A linha e o plano cefalométricos de referência foram traçados de acordo com FREITAS ${ }^{39}$, como referência para a quantificação da perda de ancoragem e estão representados na figura 5 . O termo "plano" refere-se sempre que houver três ou mais pontos cefalométricos, enquanto que o termo "linha" designa toda reta traçada a partir de dois pontos cefalométricos.

- Linha C - Linha perpendicular ao plano mandibular que parte deste e tangencia a cortical lingual externa da sínfise mandibular.

- Plano mandibular - Plano obtido pela união dos pontos de referência Go e Me, preconizado por TWEED ${ }^{95}$.

\subsubsection{4 - Grandezas lineares}

Após a determinação dos pontos, linhas e planos cefalométricos, foram obtidas as distâncias lineares, com o auxílio de esquadro e régua graduada em $0,5 \mathrm{~mm}$. As seguintes grandezas lineares podem ser observadas esquematicamente, na figura 5 .

- CM-C - Distância linear do ponto CM à linha C, paralela ao plano mandibular. 
- RM-C - Distância linear do ponto RM à linha C, paralela ao plano mandibular.

- CI-C - Distância linear do ponto CI à linha C, paralela ao plano mandibular.

- RI-C - Distância linear do ponto RI à linha C, paralela ao plano mandibular. 


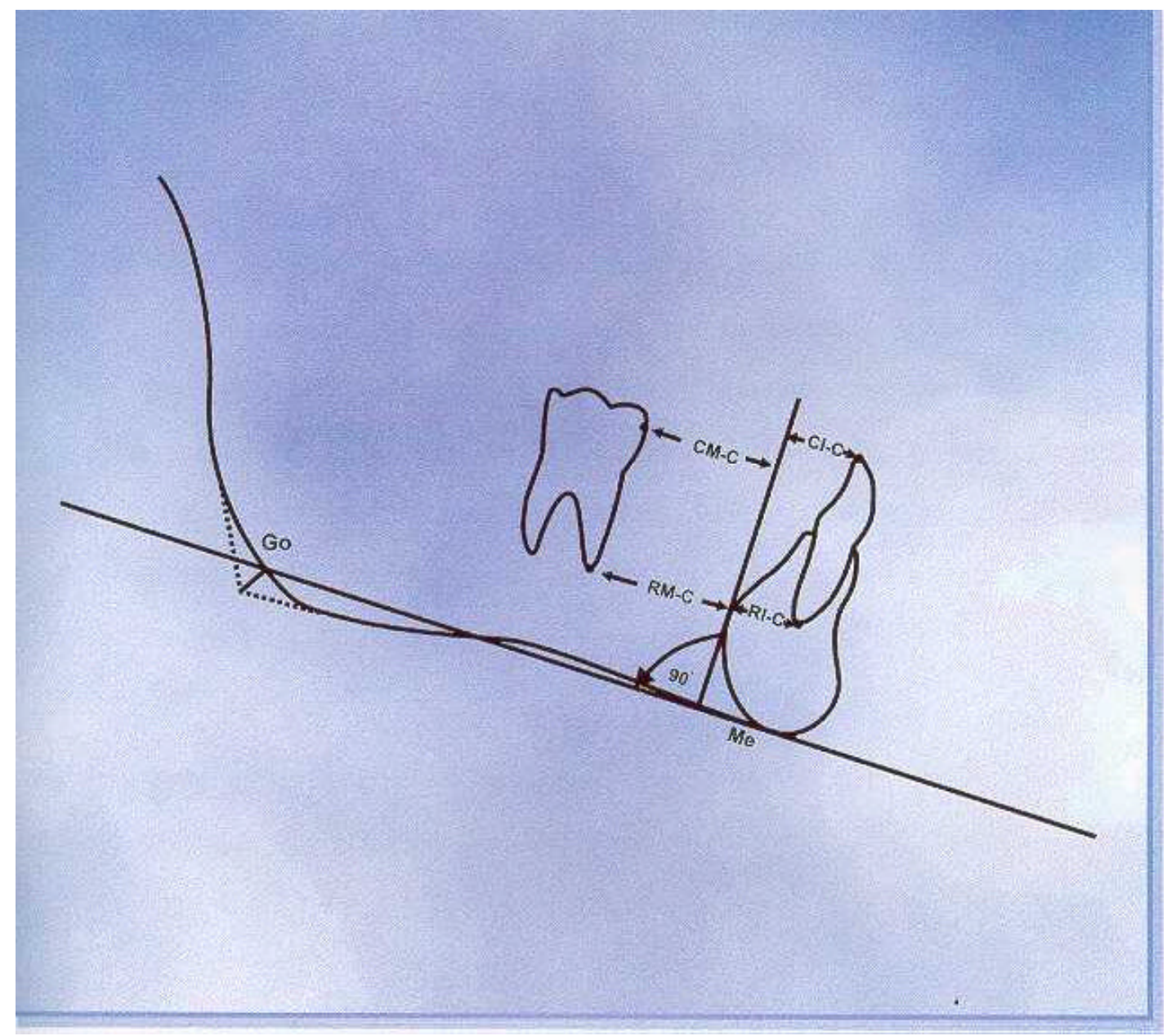

FIGURA 5 - Linha C, plano mandibular GoMe e grandezas lineares. 


\subsection{3 - Método estatístico}

Para a comparação das grandezas lineares CM-C, RM-C, CIC e RI-C entre as técnicas do Arco de Canto Simplificada (Standard Edgewise) e do Arco Reto (Straight Wire), foi utilizado o teste " $t$ " de Student para dados não emparelhados com nível de $5 \%$, a fim de se verificar a possivel existência de diferenças significativas, de acordo com COSTA NETO ${ }^{31}$. Para a aplicação deste teste, dentro de cada grandeza linear, para cada técnica, foram tomadas as médias das diferenças entre os valores final da fase de nivelamento e início de tratamento. 


\section{RESULTADOS}




\title{
5 - RESULTADOS
}

\author{
$A_{\text {lineares CM-C, RM-C, CI-C e RI-C, a quantidade de }}^{\text {pós obtidos os valores, em milímetros, das grandezas }}$
} movimentação dos molares e incisivos foi analisada, por meio da comparação entre as séries referentes às diferenças entre as fases inicial de tratamento e final de nivelamento. Os valores originais das medidas e das diferenças entre as fases encontram-se dispostos no capítulo Anexos, sendo que os valores positivos obtidos pela diferença entre a fase inicial de tratamento e final de nivelamento, indicam a ocorrência de perda de ancoragem.

Os resultados da análise estatística encontram-se expressos nas Tabelas 3, 4, 5 e 6, mostrando as principais características das grandezas lineares CM-C, RM-C, CI-C e RI-C entre as duas técnicas pesquisadas, tais como as médias e os desvios-padrão de cada série.

Uma análise global, mostra a movimentação para mesial de coroa dos molares inferiores, maior no grupo II e de raiz, maior para o grupo I. Os incisivos inferiores movimentaram-se para vestibular ao nível coronário em maior intensidade no grupo I, porém ao nivel radicular, estes mesmos dentes exibiram uma movimentação para lingual menor no grupo II. 
TABELA 3 - Medidas estatísticas e resultados do teste "t" para a distância CM-C (em milímetros)

\begin{tabular}{l|l|l}
\hline Medidas Estatísticas & \multicolumn{1}{|c|}{ Grupo I } & \multicolumn{1}{c}{ Grupo II } \\
\hline № de Pacientes & 27 & 19 \\
Média (em mm) & 0,7592 & 1,0789 \\
\hline Desvio Padrão & 1,1960 & 1,6437 \\
TESTE “t” & & \\
\hline Graus de Liberdade & 44 & \\
Valor " $\mathrm{t}$ " & 0,4487 (ns) & \\
\hline Valor "t" crítico(5\%) & 2,0154 &
\end{tabular}

ns : não significativo

TABELA 4 - Medidas estatísticas e resultados do teste "t" para a distância RM-C (em milímetros)

\begin{tabular}{l|l|l}
\hline Medidas Estatísticas & \multicolumn{1}{|c|}{ Grupo I } & \multicolumn{1}{c}{ Grupo II } \\
\hline $\mathrm{N}^{\mathrm{o}}$ de Pacientes & 27 & 19 \\
Média (em mm) & 1,6481 & 0,7105 \\
\hline Desvio Padrão & 1,4332 & 1,9742 \\
TESTE " $\mathrm{t}$ " & & \\
\hline Graus de Liberdade & 44 & \\
\hline Valor " $\mathrm{t}$ " & $0,0342 *$ & \\
\hline Valor "t" crítico(5\%) & 1,6802 &
\end{tabular}

* significativo a $5 \%$ 
TABELA 5 - Medidas estatísticas e resultados do teste "t" para a distância CI-C (em milímetros)

\begin{tabular}{l|l|l}
\hline Medidas Estatísticas & \multicolumn{1}{|c|}{ Grupo I } & \multicolumn{1}{c}{ Grupo II } \\
\hline $\mathrm{N}^{\mathbf{0}}$ de Pacientes & 27 & 19 \\
Média (em mm) & $-0,8889$ & $-0,7631$ \\
\hline Desvio Padrão & \multicolumn{2}{|c}{1,6697} \\
TESTE "t" & \\
\hline Graus de Liberdade & \multicolumn{1}{|c}{} \\
Valor " $\mathrm{t}$ " & 0,7638 (ns) & \\
\hline Valor "t" crítico(5\%) & 2,0154 &
\end{tabular}

ns : não significativo

TABELA 6 - Medidas estatísticas e resultados do teste "t" para a distância RI-C (em milímetros)

\begin{tabular}{l|l|l}
\hline Medidas Estatísticas & \multicolumn{1}{|c|}{ Grupo I } & \multicolumn{1}{c}{ Grupo II } \\
\hline $\mathrm{N}^{\mathrm{o}}$ de Pacientes & 27 & 19 \\
$\mathrm{Média}(\mathrm{em} \mathrm{mm})$ & 0,8889 & 0,7631 \\
\hline Desvio Padrão & 1,1546 & 1,6697 \\
TESTE " $\mathrm{t}$ " & & \\
\hline Graus de Liberdade & 44 & \\
Valor " $\mathrm{t}$ " & $0,7638(\mathrm{~ns})$ & \\
\hline Valor " $\mathrm{t}$ " crítico(5\%) & 2,0154 &
\end{tabular}

ns : não significativo 
6 DISCUSSÃO 


\section{6 - DISCUSSÃO}

$\mathrm{D}$ esde os primórdios da Ortodontia a ancoragem inferior vem sendo constantemente pesquisada, com o objetivo de diminuir o movimento para mesial dos dentes posteriores, visando em última instância a obtenção das principais metas do tratamento ortodôntico, que incluem a eficiência oclusal, a harmonia e a estabilidade dos dentes, bem como o equilíbrio das linhas faciais. Vários autores ${ }^{1,11,13,26,53,64,74,80,}$ idealizaram diversos tipos de ancoragem bastante eficientes e, deste modo alcançaram um maior refinamento na finalização dos tratamentos ortodônticos.

Com a técnica do Arco de Canto, ANGLE ${ }^{10}$ conseguiu introduzir a sua última e melhor invenção mecânica ("The latest and best in orthodontic mechanism"). Com esta técnica, alcançou o maior e mais desafiador objetivo da Ortodontia, qual seja o controle tridimensional da movimentação dentária. As técnicas ortodônticas mais modernas, não obstante as alterações na concepção estrutural dos acessórios, continuam a respeitar o princípio básico do aparelho do Arco de Canto, ou seja, a utilização do fio retangular.

Discípulo de Angle, TWEED ${ }^{90}$ não estava satisfeito com os constantes fracassos clínicos obtidos com a técnica do Arco de Canto original, idealizada por seu mestre. Ressaltava que, para posicionar os dentes em suas inclinações axiais corretas, havia a 
necessidade de extrações dentárias, contrapondo-se frontalmente aos princípios de Angle, que possuía a filosofia não extracionista. TWEED ${ }^{91,92}$ passou, então, a defender a necessidade do posicionamento dos dentes em suas inclinações axiais corretas, afirmando que, somente após a verticalização dos dentes pósteroinferiores em relação à sua base óssea, bem como a manutenção desta posição, se poderia utilizar estes dentes como resistência mecânica eficiente à tendência de mesialização dos mesmos, durante a utilização dos elásticos de Classe II. Esta fase do tratamento durava quatro meses em média e foi denominada de "preparo de ancoragem". TWEED ${ }^{93}$ revolucionou a Ortodontia da época ao apresentar o retratamento dos casos tratados com a técnica do Arco de Canto, só que, agora, com extrações dos primeiros pré-molares. Portanto, conseguiu provar que havia idealizado uma mecânica eficiente, quando aliada a um diagnóstico preciso.

Com a introdução do preparo de ancoragem, diversos autores ${ }^{19,72,81,84}$ criticaram o aspecto biológico que este procedimento envolvia. Apesar das contestações, os resultados clínicos conseguidos por TWEED ${ }^{94}$ superavam e alicerçavam a excelência de sua técnica.

Após a modificação que a mecânica do Arco de Canto sofreu, com a introdução do procedimento do preparo de ancoragem, várias novas técnicas foram propostas por outros autores $^{13,22,23,43,47,52,83}$, que dinamizaram ainda mais o curso do tratamento ortodôntico corretivo. Dentre elas, encontra-se a técnica do Arco Reto (Straight Wire) idealizada por ANDREWS ${ }^{3,4}$ a 
partir do clássico estudo da anatomia e da posição das coroas dos dentes na oclusão normal. Este estudo deu origem à definição das seis chaves para a oclusão normal. Desde então, estas seis chaves passaram a representar a meta terapêutica dos tratamentos ortodônticos. Os acessórios da técnica do Arco Reto foram idealizados com o intuito de facilitar a obtenção das seis características principais, ao final da mecanoterapia. Esta técnica foi denominada pelo autor de técnica do Arco de Canto "Sofisticada", por incluir nos acessórios de cada dente as características espaciais relacionadas à anatomia e à posição da coroa clínica dos mesmos, tornando-se desnecessária a confecção das dobras artísticas nos arcos de nivelamento. Esta característica mecânica deu origem ao nome "Arco Reto".

$\mathrm{Na}$ transição da técnica do Arco de Canto para a técnica do Arco Reto, uma das primeiras diferenças que se tornou aparente, foi o controle da ancoragem. Quando os fios eram encaixados no aparelho pré-ajustado, ocorria uma vestibularização dos incisivos e caninos, resultante da inclinação introduzida nos acessórios anteriores. Esta tendência era mais evidente no arco superior devido à maior quantidade de inclinação dos braquetes ânterosuperiores. Por causa deste inconveniente muitos profissionais criticaram a técnica do Arco Reto, e voltaram a utilizar a técnica do Arco de Canto convencional.

No entanto ANDREWS ${ }^{6}$, evidenciou que o controle de ancoragem necessário permanecia o mesmo, independente da técnica utilizada. Porém, se as necessidades fossem atendidas no início do tratamento e os dentes posicionados de forma ideal, na 
maioria dos casos a ancoragem poderia ser diminuída até o final do tratamento ortodôntico. Por este fator, a mecânica tornou-se mais cautelosa durante a fase de nivelamento. $O$ princípio da dobra em ômega posterior da técnica do Arco de Canto Convencional foi mantido ao se dobrar os fios imediatamente após a face distal dos molares (bent back). Este procedimento também controla a posição dos dentes anteriores enquanto os molares são mantidos em posição por meio de um recurso de ancoragem.

Outro fator que ocorreu nos primórdios da técnica do Arco Reto foi a utilização de elásticos intramaxilares em cadeia para prevenir que os dentes anteriores inclinassem para vestibular, durante a fase de nivelamento. O problema resultante deste procedimento em casos com extração, foi a inclinação para distal dos dentes anteriores, que provocava a abertura de mordida na área dos pré-molares e o aprofundamento da mordida na região anterior. Ao menos que a inclinação para distal fosse excessiva, esta situação poderia ser corrigida normalmente, contudo despenderia maior tempo durante a fase de nivelamento e, consequentemente, o tempo total de tratamento seria aumentado.

Para solucionar este problema, ANDREWS ${ }^{7}$ desenvolveu dois conjuntos de acessórios anteriores para serem utilizados em casos com e sem extração. Para o conjunto indicado em casos com extração, idealizou uma série de acessórios para os caninos e dentes posteriores de acordo com as necessidades de cada caso. Por último, foram adicionados ganchos denominados de braços 
de força, para que as forças pudessem ser aplicadas o mais próximo possivel do centro de resistência dos dentes.

A partir de então, várias técnicas foram propostas baseadas no princípio original da técnica do Arco Reto, variando-se somente as prescrições de angulação, torque e off-set distal dos acessórios. A prescrição da técnica do Arco Reto utilizada neste estudo foi a preconizada por $\mathrm{ROTH}^{79,80}$, de acordo com sua mecânica e necessidades de tratamento.

Com o intuito de comparar as técnicas do Arco de Canto Simplificada e do Arco Reto, foi realizada esta pesquisa para analisar a efetividade do sistema de ancoragem durante a fase de nivelamento do tratamento ortodôntico corretivo.

Primeiramente, convém ressaltar o termo nivelamento, que engloba os procedimentos tanto de alinhamento quanto de nivelamento dos dentes. Estas duas situações distintas devem ser corretamente diferenciadas. $\mathrm{O}$ alinhamento visa o posicionamento correto dos dentes nos arcos dentários, nos sentidos mesiodistal e vestibulolingual. Já o nivelamento propriamente dito, corresponde à colocação dos dentes em posição correta no sentido vertical, corrigindo más posições dentárias de intrusão e extrusão.

A fase de nivelamento inicia-se logo no início do posicionamento dos acessórios. Tanto na técnica do Arco de Canto Simplificada quanto na do Arco Reto, se os acessórios não forem posicionados de modo preciso na superfície vestibular dos dentes, ocorrerá um mau posicionamento dentário nos sentidos 
horizontal e vertical, bem como uma inclinação axial inadequada dos dentes.

O nivelamento por sua vez, pode ser subdividido clinicamente em quatro fases principais. Primeiramente deve-se priorizar o nivelamento das regiões posteriores, superior e inferior. A segunda fase envolve a retração inicial dos caninos. Logo em seguida parte-se para o nivelamento dos segmentos anteriores, superior e inferior. E, por último, o aumento progressivo no diâmetro dos fios ortodônticos.

$\mathrm{Na}$ técnica do Arco de Canto Simplificada o nivelamento das regiões posteriores, superior e inferior, pode ser realizado de duas maneiras : com arcos segmentados e seccionados de aço inoxidável 0,016" ou com arcos segmentados de aço inoxidável 0,016". Os arcos segmentados compreendem um segmento de arco, ao contrário dos arcos contínuos. Os arcos são seccionados quanto possuem dobras verticais no fio, dentre elas as dobras em ômega e as alças idealizadas por $\mathrm{BEGG}^{13}$. No grupo I, utilizaramse somente os arcos segmentados sem as alças de Begg. Estes segmentos de arco estenderam-se desde a face distal dos primeiros molares até a face mesial dos caninos, apresentando dobras em ômega posteriores para conferir maior estabilidade do arco, assim como dobras na mesial dos caninos para evitar lesões aos tecidos bucais.

A segunda fase, retração inicial dos caninos, também é executada com o auxílio de arcos segmentados com fio de aço inoxidável 0,016". Estes arcos, além dos ômegas, possuem duas características principais : o ângulo caudal, no plano vertical e o 
desvio caudal, no plano horizontal. A finalidade destas dobras é evitar o deslocamento vestibular dos caninos e dos molares durante esta fase do nivelamento. A principal finalidade da retração inicial dos caninos é a de retraí-los o suficiente para obter espaço para o alinhamento e nivelamento dos incisivos. Esta retração inicial deve ser realizada no menor espaço de tempo possivel, contanto que atinja seus objetivos. O uso prolongado dos elásticos intramaxilares em cadeia, nesta fase do nivelamento, acarreta uma inclinação mesiolingual indesejada dos dentes posteriores (rolling). Nesta fase é importante lembrar que os dentes posteriores devem estar conjugados com amarrilhos metálicos e deve ter sido iniciada a utilização do sistema de ancoragem, composto pelo aparelho extrabucal, placa lábio ativa e elásticos de Classe III.

$\mathrm{Na}$ técnica do Arco Reto, utilizam-se fios de ligadura metálica (0,010") denominados de "lace back" que são colocados em cada quadrante do último molar bandado até os caninos, na tentativa de evitar o efeito indesejável das forças elásticas nesta fase do nivelamento. Apesar da ausência de tensão elástica, os lace back não somente previnem que as coroas dos caninos se inclinem para anterior, mas resultam no surpreendente efeito do movimento para distal dos caninos sem o efeito de inclinação que ocorre com elásticos em cadeia.

Para os pacientes do grupo I, o nivelamento dos segmentos anteriores, superior e inferior foi realizado com fio Twist-flex 0,0175". Após o alinhamento e nivelamento dos incisivos, iniciouse o aumento progressivo no diâmetro dos fios até chegar no arco 
retangular passivo 0,021" X 0,025", com o intuito de respeitar a fisiologia dos tecidos periodontais. Esta seqüência de fios deve iniciar com o fio redondo de aço inoxidável 0,016" sem dobras, passando pelos fios 0,018" e 0,020" com dobras de $1^{\text {a }}$ ordem e finalizando com o fio retangular 0,021" X 0,025" com dobras de $1^{\mathrm{a}}, 2^{\mathrm{a}}$ e $3^{\mathrm{a}}$ ordens. As dobras de $1^{\mathrm{a}}$ ordem correspondem aos "insets" e "off-sets" realizados no arco superior referentes respectivamente aos incisivos laterais e caninos. No arco inferior, não se executam dobras no fio redondo, com exceção dos off-sets de caninos, quando a face vestibular desse dente apresentar-se muito saliente, o que conduz à sua lingualização. As dobras de $2^{\text {a }}$ ordem são aquelas efetuadas no sentido vertical, como as dobras em "v" (" $v$ " bends) realizadas no fio retangular. Finalmente, as dobras de $3^{a}$ ordem correspondem aos torques, ou seja, torções realizadas nos fios de secção retangular no sentido de seu longo eixo. A confecção de todos esses arcos deve respeitar a conformação dos arcos dentários de cada paciente. Para a padronização na confecção dos arcos, utiliza-se como recurso auxiliar o diagrama idealizado por INTERLANDI ${ }^{51}$, que pesquisou os raios de curvatura anterior dos arcos dentários que ocorriam com maior freqüência na população.

A partir do fio 0,016" os arcos devem ter como objetivo a planificação ou redução da curva de Spee ou, até mesmo, a sua acentuação no arco superior e reversão no arco inferior. Do fio 0,018" em diante, deve-se conjugar os segmentos anteriores com amarrilho metálico. Desta forma, evita-se a abertura de diastemas e fortalece-se a ancoragem durante a fase de nivelamento. $\mathrm{Na}$ 
última fase do nivelamento, emprega-se o arco retangular 0,021" $\mathrm{X}$ 0,025" com torques passivos, exceto na região dos caninos, onde se utiliza torque neutro.

A seqüência de fios utilizada durante a fase de nivelamento nos pacientes do grupo II foram os fios redondos 0,014" e 0,016" de níquel-titânio, seguidos dos fios redondos de aço inoxidável 0,016", 0,018" e 0,020" e finalizando com o arco retangular 0,018" X 0,025". Todos eles sem nenhum tipo de dobra, somente os bent back nas extremidades dos fios.

A amostra desta pesquisa foi composta pelo número de 46 pacientes, 27 do grupo I e 19 do grupo II. O grupo II, da técnica do Arco Reto, foi composto por um número menor de pacientes justamente pelo fato dos alunos do curso de Pós-graduação utilizarem a técnica do arco de canto na maioria de seus pacientes. Este número reduzido não altera significativamente e também não prejudica os resultados obtidos por meio dos testes estatísticos.

$\mathrm{Na}$ verdade, o intuito desta pesquisa foi avaliar comparativamente a perda de ancoragem inferior entre as técnicas arco de canto e arco reto, durante a fase de nivelamento. Pois é nesta fase que as duas técnicas mais se diferem, além da configuração dos braquetes ser a principal diferença. O ideal seria ter avaliado esta perda de ancoragem ao longo de todas as fases do tratamento ortodôntico corretivo. FREITAS ${ }^{39}$ teve esta preocupação ao comparar a técnica arco de canto convencional e a técnica arco de canto com o preparo de ancoragem. A mesma preocupação apresentou MARINHO ${ }^{61}$, quando comparou 
cefalometricamente o tratamento realizado com o arco de trabalho da técnica de Tweed com os braquetes angulados da técnica de Holdaway. Todas as fases do tratamento ortodôntico também foram os objetivos principais da pesquisa de CIPRIANO; VIGORITO; RINO NETO ${ }^{28}$, na qual avaliaram cefalometricamente o comportamento da ancoragem inferior, comparando a angulação de braquetes de 3 e 5 graus. Numa futura pesquisa reside a possibilidade de comparação da técnica arco de canto simplificada com a técnica do arco reto, no que tange ao assunto ancoragem, até o final do tratamento ortodôntico corretivo. Nesta segunda oportunidade de pesquisa, o objetivo seria a avaliação do tratamento entre as fases inicial e final de nivelamento, da fase de nivelamento até a fase de retração dos segmentos anteriores e, dessa, até o final do tratamento.

Uma vez realizadas estas considerações, julga-se oportuno passar para a discussão dos resultados alcançados neste estudo.

$\mathrm{Na}$ amostra estudada foram analisadas as grandezas lineares CM-C e RM-C, para quantificar a movimentação dos molares inferiores e as medidas CI-C e RI-C, para verificar a movimentação dos incisivos inferiores.

As médias das grandezas lineares de cada uma das técnicas analisadas (grupos I e II), foram comparadas por meio do teste "t" de Student. As tabelas 3, 4, 5 e 6, expostas no capítulo de Resultados, apresentam as medidas estatísticas e os resultados do teste "t", respectivamente, para as variáveis CM-C, RM-C, CIC e RI-C. 


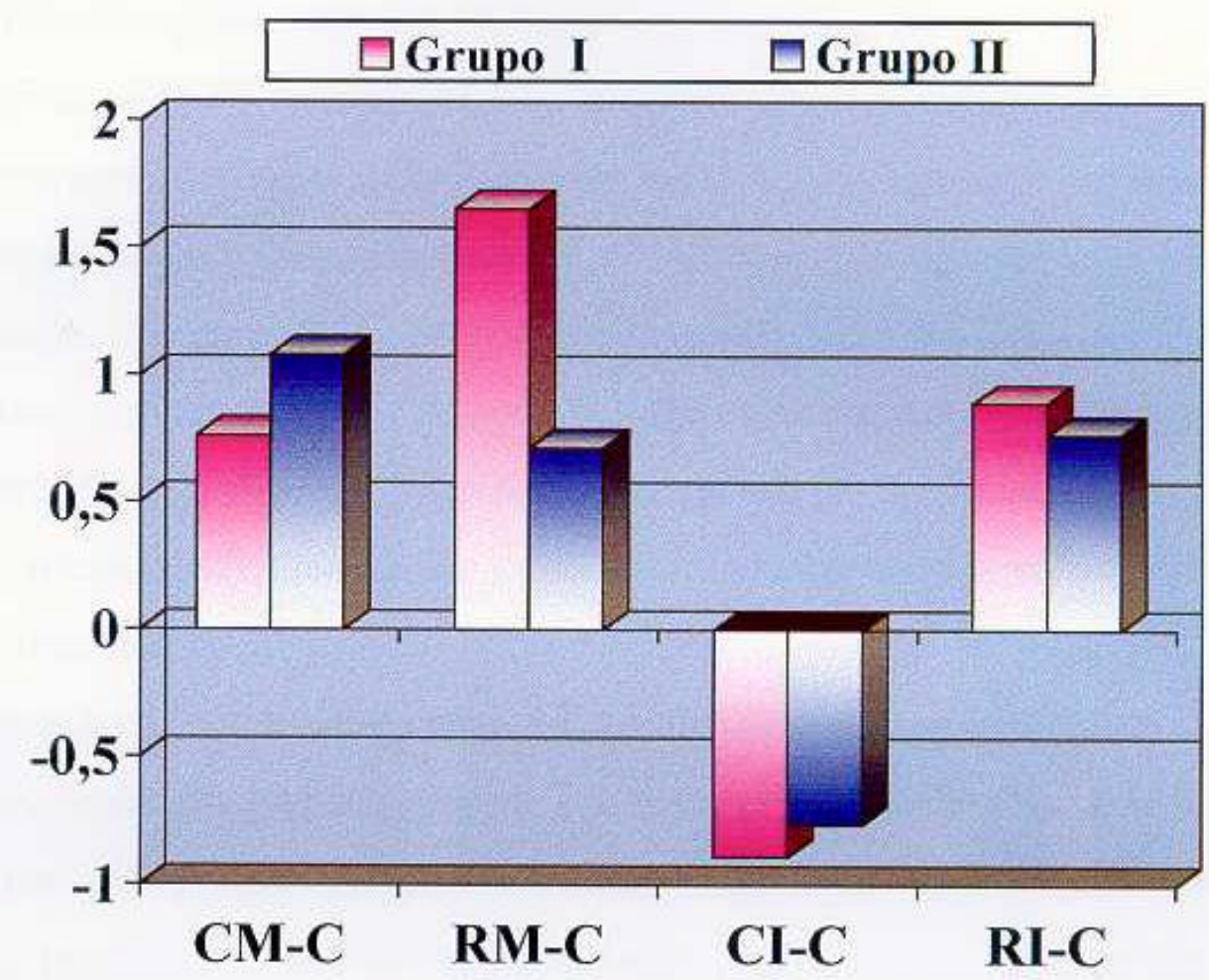

FIGURA 6 - Gráfico indicativo das diferenças médias para as grandezas lineares CM-C, RM-C, CI-C e RI-C, nas técnicas do Arco de Canto Simplificada (grupo I) e Arco Reto (grupo II). 
A figura 6 apresenta o gráfico demonstrando as diferenças médias para as grandezas lineares estudadas, entre os grupos I e II. Neste gráfico, pode-se observar a movimentação em milimetros, que ocorreu nos dentes molares e incisivos entre as técnicas do Arco de Canto Simplificada e do Arco Reto.

A medida CM-C evidenciou o deslocamento mesial que a coroa do primeiro molar inferior apresentou. No grupo I, esta medida indicou a ocorrência de uma perda de ancoragem de 0,76 $\mathrm{mm}$, em média. No grupo II, este valor foi de 1,08 mm. Apesar de ser um valor maior que o grupo I, não apresentou diferença estatisticamente significante. Esta diferença pode ter fundamento pelo menor atrito dos acessórios com os arcos de nivelamento na técnica do Arco Reto.

Em relação à movimentação da coroa do incisivo inferior, a variável CI-C indicou para o grupo I uma vestibularização média de $0,88 \mathrm{~mm}$. O grupo II apresentou a mesma tendência de movimento, porém em menor quantidade $(0,76 \mathrm{~mm})$. Apesar da não significância estatística entre os dois grupos, pode-se relacionar a menor inclinação para vestibular na técnica do Arco Reto ao uso dos amarilhos conjugados (lace back) e da dobras distais (bent back) durante a fase de nivelamento. Resultados semelhantes foram encontrados por ROBINSON ${ }^{77}$ quando avaliou a técnica do Arco Reto comparando casos com e sem a colocação de amarrilhos conjugados até os caninos. Observou que os molares inferiores se movimentaram para mesial cerca de 1,76 $\mathrm{mm}$ nos casos onde se utilizaram amarrilhos conjugados, e 1,53 $\mathrm{mm}$ quando estes não foram utilizados. Os incisivos inferiores 
inclinaram-se $1 \mathrm{~mm}$ para lingual, em média, quando se utilizaram os amarrilhos, porém inclinaram-se 1,47 $\mathrm{mm}$ para vestibular quando não se efetuou a conjugação dos segmentos posteriores.

A movimentação radicular do incisivo inferior ocorreu para o sentido lingual nos dois grupos, com maior intensidade no grupo I $(0,88 \mathrm{~mm})$. Isto se explica pela análise do centro de resistência e pela conseqüência natural do movimento de inclinação que conduz a coroa e a raiz a direções opostas. O grupo II exibiu movimento lingual de raiz de 0,76 $\mathrm{mm}$, movimento este que não apresentou diferença estatisticamente significativa quando comparado ao grupo I.

A única variável que mostrou diferença estatisticamente significante foi a RM-C. Esta variável relaciona linearmente a raiz do primeiro molar inferior à linha "C" de referência e mostrou diferença estatisticamente significativa a $5 \%$ entre os dois grupos, indicando uma perda de ancoragem radicular do primeiro molar inferior maior para o grupo I (Arco de Canto Simplificada), que foi de 1,65 mm, em comparação ao grupo II (Arco Reto), que foi de $0,71 \mathrm{~mm}$. Este fato é de explicação relativamente dificil, tendo em vista que ambas as técnicas apresentam uma grande semelhança para a quase totalidade dos procedimentos mecânicos empregados durante as etapas iniciais do tratamento ortodôntico. Deste modo, para explicarmos esta diferença devemos lançar mão de algumas hipóteses, que necessitarão de averiguação em investigações posteriores. 
Primeiramente, podemos considerar que talvez tenham ocorrido diferenças casuais quanto à colaboração dos pacientes no que tange à utilização da placa lábio ativa e dos elásticos de Classe III. Assim a maior colaboração quanto à utilização dos recursos de ancoragem poderia, de maneira absolutamente fortuita, acarretar diferenças entre os grupos no que se refere à perda de ancoragem. Contudo, a determinação exata e infalivel do nível de colaboração dos pacientes ainda constitui apenas um ideal a ser perseguido, mas quase impossivel de ser alcançado, o que torna particularmente difícil a realização de estudos comparativos desta natureza.

Uma segunda hipótese que poderia ser aventada na tentativa de explicar esta diferença quanto a movimentação apical dos molares, reside no grau de sobremordida e na profundidade da curva de Spee apresentada pelos pacientes tratados em cada um dos grupos analisados. Desta maneira, se o grupo I apresentou uma curva de Spee mais profunda, associada a uma maior sobremordida anterior, estes casos devem ter requerido uma maior reversão na convexidade vertical dos arcos ortodônticos. Este fato poderia conduzir a um momento de rotação axial dos molares gerando mesialização apical, mas sem distalização coronária, devido à existência de pontos de contato firmes com os segundos molares, impedindo a rotação coronária para distal. Este mesmo mecanismo, poderia explicar o maior movimento para vestibular das coroas dos incisivos inferiores. Portanto, seria muito interessante o desenvolvimento de 
pesquisas futuras avaliando a influência da curva de Spee na perda de ancoragem inferior. 
7 CONCLUSÕES 


\section{7 - CONCLUSÕES}

$\mathrm{D}$ iante do que foi exposto, discutido e, com base na metodologia empregada nesta pesquisa pode-se concluir que durante a fase de nivelamento, comparando-se as técnicas do Arco de Canto Simplificada e do Arco Reto (os grupos I e II respectivamente), conclui-se que :

7.1 - A coroa do primeiro molar inferior apresentou perda de ancoragem com maior intensidade no grupo II, porém estatisticamente não significante.

7.2 - O grupo I exibiu maior migração radicular para mesial do primeiro molar inferior, alcançando significância estatística.

7.3 - Os incisivos inferiores exibiram inclinação coronária para vestibular em ambas as técnicas, todavia apresentando uma maior intensidade no grupo I, mas sem significância estatística.

7.4 - O grupo II apresentou menor inclinação radicular dos incisivos inferiores para lingual, embora estatisticamente não significante. 
ANEXOS 


\section{ANEXOS}

ANEXO 1 - Valores cefalométricos obtidos de cada paciente, para a distância CM-C, em milímetros, ao início do tratamento e ao término da fase de nivelamento

\begin{tabular}{|c|c|c|c|c|c|}
\hline \multicolumn{6}{|c|}{$\mathbf{C M}-\mathbf{C}$} \\
\hline & \multicolumn{2}{|c|}{ GRUPO I - ARCO DE CANTO } & \multicolumn{3}{|c|}{ GRUPO II - ARCO RETO } \\
\hline & 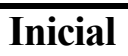 & Final & & Inicial & Final \\
\hline 01 & 13,5 & 11,0 & 01 & 13,0 & 13,5 \\
\hline 02 & 11,5 & 10,5 & 02 & 16,0 & 15,0 \\
\hline 03 & 13,0 & 14,0 & 03 & 17,0 & 16,5 \\
\hline 04 & 14,0 & 13,5 & 04 & 14,5 & 13,0 \\
\hline 05 & 14,5 & 13,0 & 05 & 19,5 & 20,0 \\
\hline 06 & 12,0 & 12,0 & 06 & 14,0 & 13,0 \\
\hline 07 & 16,0 & 16,0 & 07 & 14,5 & 12,0 \\
\hline 08 & 13,0 & 12,0 & 08 & 18,5 & 15,0 \\
\hline 09 & 14,0 & 12,0 & 09 & 16,0 & 12,5 \\
\hline 10 & 17,0 & 15,5 & 10 & 13,0 & 14,0 \\
\hline 11 & 17,0 & 17,0 & 11 & 10,5 & 12,0 \\
\hline 12 & 18,0 & 15,0 & 12 & 16,0 & 16,5 \\
\hline 13 & 16,5 & 15,5 & 13 & 13,0 & 10,0 \\
\hline 14 & 12,0 & 12,0 & 14 & 11,0 & 12,5 \\
\hline 15 & 19,0 & 17,5 & 15 & 16,0 & 14,0 \\
\hline 16 & 15,5 & 15,5 & 16 & 12,5 & 9,5 \\
\hline 17 & 14,5 & 16,5 & 17 & 13,5 & 12,5 \\
\hline 18 & 10,5 & 9,5 & 18 & 13,5 & 11,5 \\
\hline 19 & 18,0 & 15,0 & 19 & 16,0 & 14,5 \\
\hline 20 & 15,5 & 15,5 & & & \\
\hline 21 & 17,0 & 17,5 & & & \\
\hline 22 & 15,0 & 13,0 & & & \\
\hline 23 & 14,0 & 15,0 & & & \\
\hline 24 & 13,5 & 13,0 & & & \\
\hline 25 & 15,0 & 14,0 & & & \\
\hline 26 & 16,0 & 15,0 & & & \\
\hline 27 & 15,0 & 14,0 & & & \\
\hline
\end{tabular}


ANEXO 2 - Valores cefalométricos obtidos de cada paciente, para a distância RM-C, em milímetros, ao início do tratamento e ao término da fase de nivelamento

\begin{tabular}{|ll|c|cc|c|}
\hline \multicolumn{7}{|c|}{ RM - C } \\
\hline \multicolumn{7}{|c|}{ GRUPO I - ARCO DE CANTO } & \multicolumn{3}{c|}{ GRUPO II - ARCO RETO } \\
\hline \multicolumn{2}{|c|}{ Inicial } & Final & \multicolumn{2}{c|}{ Inicial } & Final \\
\hline $\mathbf{0 1}$ & 12,0 & 9,5 & $\mathbf{0 1}$ & 12,0 & 14,5 \\
\hline $\mathbf{0 2}$ & 10,5 & 10,0 & $\mathbf{0 2}$ & 15,0 & 15,0 \\
\hline $\mathbf{0 3}$ & 12,5 & 11,0 & $\mathbf{0 3}$ & 16,0 & 13,0 \\
\hline $\mathbf{0 4}$ & 13,0 & 11,0 & $\mathbf{0 4}$ & 13,5 & 13,5 \\
\hline $\mathbf{0 5}$ & 14,0 & 13,5 & $\mathbf{0 5}$ & 19,0 & 19,0 \\
\hline $\mathbf{0 6}$ & 14,0 & 11,5 & $\mathbf{0 6}$ & 13,0 & 12,0 \\
\hline $\mathbf{0 7}$ & 17,5 & 14,0 & $\mathbf{0 7}$ & 15,5 & 16,0 \\
\hline $\mathbf{0 8}$ & 13,0 & 10,0 & $\mathbf{0 8}$ & 16,5 & 14,0 \\
\hline $\mathbf{0 9}$ & 14,0 & 12,0 & $\mathbf{0 9}$ & 14,0 & 11,5 \\
\hline $\mathbf{1 0}$ & 17,0 & 14,5 & $\mathbf{1 0}$ & 12,0 & 14,0 \\
\hline $\mathbf{1 1}$ & 16,0 & 16,0 & $\mathbf{1 1}$ & 10,0 & 12,0 \\
\hline $\mathbf{1 2}$ & 18,0 & 16,0 & $\mathbf{1 2}$ & 16,0 & 18,0 \\
\hline $\mathbf{1 3}$ & 14,5 & 12,0 & $\mathbf{1 3}$ & 13,0 & 12,0 \\
\hline $\mathbf{1 4}$ & 11,0 & 8,0 & $\mathbf{1 4}$ & 11,0 & 11,5 \\
\hline $\mathbf{1 5}$ & 14,5 & 13,0 & $\mathbf{1 5}$ & 14,5 & 12,0 \\
\hline $\mathbf{1 6}$ & 16,0 & 14,5 & $\mathbf{1 6}$ & 13,0 & 9,0 \\
\hline $\mathbf{1 7}$ & 12,5 & 14,0 & $\mathbf{1 7}$ & 12,0 & 10,5 \\
\hline $\mathbf{1 8}$ & 13,0 & 9,0 & $\mathbf{1 8}$ & 14,0 & 11,0 \\
\hline $\mathbf{1 9}$ & 19,0 & 15,5 & $\mathbf{1 9}$ & 16,0 & 14,0 \\
\hline $\mathbf{2 0}$ & 16,0 & 14,0 & & & \\
\hline $\mathbf{2 1}$ & 16,0 & 15,0 & & & \\
\hline $\mathbf{2 2}$ & 16,5 & 13,5 & & & \\
\hline $\mathbf{2 3}$ & 14,5 & 15,0 & & & \\
\hline $\mathbf{2 4}$ & 14,0 & 13,5 & & & \\
\hline $\mathbf{2 5}$ & 14,5 & 12,0 & & & \\
\hline $\mathbf{2 6}$ & 17,0 & 18,0 & & & \\
\hline $\mathbf{2 7}$ & 15,0 & 15,0 & & & \\
\hline & & & & & \\
\hline
\end{tabular}


ANEXO 3 - Valores cefalométricos obtidos de cada paciente, para a distância CI-C, em milímetros, ao início do tratamento e ao término da fase de nivelamento

\begin{tabular}{|ll|c|cc|c|}
\hline \multicolumn{7}{|c|}{ CI - C } \\
\hline \multicolumn{7}{|c|}{ GRUPO I - ARCO DE CANTO } & \multicolumn{3}{c|}{ GRUPO II - ARCO RETO } \\
\hline \multicolumn{2}{|c|}{ Inicial } & Final & \multicolumn{2}{c|}{ Inicial } & Final \\
\hline $\mathbf{0 1}$ & 8,0 & 8,5 & $\mathbf{0 1}$ & 7,0 & 9,5 \\
\hline $\mathbf{0 2}$ & 8,0 & 7,5 & $\mathbf{0 2}$ & 4,0 & 5,0 \\
\hline $\mathbf{0 3}$ & 5,0 & 4,0 & $\mathbf{0 3}$ & 6,5 & 7,0 \\
\hline $\mathbf{0 4}$ & 7,5 & 8,0 & $\mathbf{0 4}$ & 9,0 & 8,0 \\
\hline $\mathbf{0 5}$ & 8,0 & 9,0 & $\mathbf{0 5}$ & 3,0 & 6,0 \\
\hline $\mathbf{0 6}$ & 5,5 & 6,5 & $\mathbf{0 6}$ & 2,5 & 5,0 \\
\hline $\mathbf{0 7}$ & 5,0 & 5,5 & $\mathbf{0 7}$ & 9,0 & 9,5 \\
\hline $\mathbf{0 8}$ & 3,5 & 6,0 & $\mathbf{0 8}$ & 7,0 & 6,0 \\
\hline $\mathbf{0 9}$ & 7,0 & 7,5 & $\mathbf{0 9}$ & 1,0 & 4,0 \\
\hline $\mathbf{1 0}$ & 2,0 & 1,5 & $\mathbf{1 0}$ & 12,0 & 10,0 \\
\hline $\mathbf{1 1}$ & 2,5 & 3,5 & $\mathbf{1 1}$ & 8,5 & 9,0 \\
\hline $\mathbf{1 2}$ & 3,0 & 6,0 & $\mathbf{1 2}$ & 1,0 & $-0,5$ \\
\hline $\mathbf{1 3}$ & 2,5 & 4,5 & $\mathbf{1 3}$ & 5,0 & 7,0 \\
\hline $\mathbf{1 4}$ & 7,0 & 9,0 & $\mathbf{1 4}$ & 8,5 & 7,0 \\
\hline $\mathbf{1 5}$ & 6,5 & 8,0 & $\mathbf{1 5}$ & 3,0 & 5,0 \\
\hline $\mathbf{1 6}$ & 9,5 & 7,0 & $\mathbf{1 6}$ & 7,0 & 9,5 \\
\hline $\mathbf{1 7}$ & 3,0 & 4,0 & $\mathbf{1 7}$ & 6,5 & 5,5 \\
\hline $\mathbf{1 8}$ & 12,0 & 13,0 & $\mathbf{1 8}$ & 11,0 & 12,5 \\
\hline $\mathbf{1 9}$ & 4,5 & 5,5 & $\mathbf{1 9}$ & 2,5 & 3,5 \\
\hline $\mathbf{2 0}$ & 3,5 & 4,5 & & & \\
\hline $\mathbf{2 1}$ & 3,0 & 3,5 & & & \\
\hline $\mathbf{2 2}$ & 8,0 & 9,0 & & & \\
\hline $\mathbf{2 3}$ & 11,5 & 13,5 & & & \\
\hline $\mathbf{2 4}$ & 8,0 & 9,0 & & & \\
\hline $\mathbf{2 5}$ & 3,5 & 5,0 & & & \\
\hline $\mathbf{2 6}$ & $-1,0$ & $-1,0$ & & & \\
\hline $\mathbf{2 7}$ & 5,0 & 7,5 & & & \\
\hline & & & & & \\
\hline
\end{tabular}


ANEXO 4 - Valores cefalométricos obtidos de cada paciente, para a distância RI-C, em milímetros, ao início do tratamento e ao término da fase de nivelamento

\begin{tabular}{|ll|c|cc|c|}
\hline \multicolumn{7}{|c|}{ RI - C } \\
\hline \multicolumn{7}{|c|}{ GRUPO I - ARCO DE CANTO } & \multicolumn{3}{c|}{ GRUPO II - ARCO RETO } \\
\hline \multicolumn{2}{|c|}{ Inicial } & Final & \multicolumn{2}{|c|}{ Inicial } & Final \\
\hline $\mathbf{0 1}$ & 4,0 & 3,5 & $\mathbf{0 1}$ & 5,5 & 3,0 \\
\hline $\mathbf{0 2}$ & 6,0 & 6,5 & $\mathbf{0 2}$ & 6,0 & 5,0 \\
\hline $\mathbf{0 3}$ & 5,0 & 6,0 & $\mathbf{0 3}$ & 3,5 & 3,0 \\
\hline $\mathbf{0 4}$ & 4,5 & 4,0 & $\mathbf{0 4}$ & 6,5 & 7,5 \\
\hline $\mathbf{0 5}$ & 5,0 & 4,0 & $\mathbf{0 5}$ & 6,0 & 3,0 \\
\hline $\mathbf{0 6}$ & 5,0 & 4,0 & $\mathbf{0 6}$ & 4,0 & 1,5 \\
\hline $\mathbf{0 7}$ & 5,0 & 4,5 & $\mathbf{0 7}$ & 5,5 & 5,0 \\
\hline $\mathbf{0 8}$ & 5,0 & 2,5 & $\mathbf{0 8}$ & 4,0 & 5,0 \\
\hline $\mathbf{0 9}$ & 4,0 & 3,5 & $\mathbf{0 9}$ & 5,0 & 2,0 \\
\hline $\mathbf{1 0}$ & 4,0 & 4,5 & $\mathbf{1 0}$ & 9,0 & 11,0 \\
\hline $\mathbf{1 1}$ & 5,0 & 4,0 & $\mathbf{1 1}$ & 5,0 & 4,5 \\
\hline $\mathbf{1 2}$ & 5,5 & 2,5 & $\mathbf{1 2}$ & 7,0 & 8,5 \\
\hline $\mathbf{1 3}$ & 4,0 & 2,0 & $\mathbf{1 3}$ & 6,0 & 4,0 \\
\hline $\mathbf{1 4}$ & 5,5 & 3,5 & $\mathbf{1 4}$ & 4,0 & 5,5 \\
\hline $\mathbf{1 5}$ & 7,0 & 5,5 & $\mathbf{1 5}$ & 5,5 & 3,5 \\
\hline $\mathbf{1 6}$ & 5,0 & 7,5 & $\mathbf{1 6}$ & 3,5 & 1,0 \\
\hline $\mathbf{1 7}$ & 3,5 & 2,5 & $\mathbf{1 7}$ & 5,0 & 6,0 \\
\hline $\mathbf{1 8}$ & 7,0 & 6,0 & $\mathbf{1 8}$ & 4,5 & 3,0 \\
\hline $\mathbf{1 9}$ & 5,0 & 4,0 & $\mathbf{1 9}$ & 5,0 & 4,0 \\
\hline $\mathbf{2 0}$ & 5,5 & 4,5 & & & \\
\hline $\mathbf{2 1}$ & 4,5 & 4,0 & & & \\
\hline $\mathbf{2 2}$ & 8,0 & 7,0 & & & \\
\hline $\mathbf{2 3}$ & 6,0 & 4,0 & & & \\
\hline $\mathbf{2 4}$ & 5,0 & 4,0 & & & \\
\hline $\mathbf{2 5}$ & 5,5 & 4,0 & & & \\
\hline $\mathbf{2 6}$ & 6,0 & 6,0 & & & \\
\hline $\mathbf{2 7}$ & 4,5 & 2,0 & & & \\
\hline & & & & & \\
\hline
\end{tabular}


ANEXO 5 - Diferenças da distância CM-C, em milimetros, de cada paciente entre o valor ao início do tratamento e ao final da fase de nivelamento

\begin{tabular}{|l|c|l|c|}
\hline \multicolumn{5}{|c|}{ CM - C } \\
\hline & GRUPO I & \multicolumn{2}{c|}{ GRUPO II } \\
\hline $\mathbf{0 1}$ & 2,5 & $\mathbf{0 1}$ & $-0,5$ \\
\hline $\mathbf{0 2}$ & 1,0 & $\mathbf{0 2}$ & 1,0 \\
\hline $\mathbf{0 3}$ & $-1,0$ & $\mathbf{0 3}$ & 0,5 \\
\hline $\mathbf{0 4}$ & 0,5 & $\mathbf{0 4}$ & 1,5 \\
\hline $\mathbf{0 5}$ & 1,5 & $\mathbf{0 5}$ & $-0,5$ \\
\hline $\mathbf{0 6}$ & 0,0 & $\mathbf{0 6}$ & 1,0 \\
\hline $\mathbf{0 7}$ & 0,0 & $\mathbf{0 7}$ & 2,5 \\
\hline $\mathbf{0 8}$ & 1,0 & $\mathbf{0 8}$ & 3,5 \\
\hline $\mathbf{0 9}$ & 2,0 & $\mathbf{0 9}$ & 3,5 \\
\hline $\mathbf{1 0}$ & 1,5 & $\mathbf{1 0}$ & $-1,0$ \\
\hline $\mathbf{1 1}$ & 0,0 & $\mathbf{1 1}$ & $-1,5$ \\
\hline $\mathbf{1 2}$ & 3,0 & $\mathbf{1 2}$ & $-0,5$ \\
\hline $\mathbf{1 3}$ & 1,0 & $\mathbf{1 3}$ & 3,0 \\
\hline $\mathbf{1 4}$ & 0,0 & $\mathbf{1 4}$ & $-1,5$ \\
\hline $\mathbf{1 5}$ & 1,5 & $\mathbf{1 5}$ & 2,0 \\
\hline $\mathbf{1 6}$ & 0,0 & $\mathbf{1 6}$ & 3,0 \\
\hline $\mathbf{1 7}$ & $-2,0$ & $\mathbf{1 7}$ & 1,0 \\
\hline $\mathbf{1 8}$ & 1,0 & $\mathbf{1 8}$ & 2,0 \\
\hline $\mathbf{1 9}$ & 3,0 & $\mathbf{1 9}$ & 1,5 \\
\hline $\mathbf{2 0}$ & 0,0 & & \\
\hline $\mathbf{2 1}$ & $-0,5$ & & \\
\hline $\mathbf{2 2}$ & 2,0 & & \\
\hline $\mathbf{2 3}$ & $-1,0$ & & \\
\hline $\mathbf{2 4}$ & 0,5 & & \\
\hline $\mathbf{2 5}$ & 1,0 & & \\
\hline $\mathbf{2 6}$ & 1,0 & & \\
\hline $\mathbf{2 7}$ & 1,0 & & \\
\hline
\end{tabular}


ANEXO 6 - Diferenças da distância RM-C, em milímetros, de cada paciente entre o valor ao início do tratamento e ao final da fase de nivelamento

\begin{tabular}{|l|c|c|c|}
\hline \multicolumn{5}{|c|}{ RM - C } \\
\hline & GRUPO I & \multicolumn{2}{c|}{ GRUPO II } \\
\hline $\mathbf{0 1}$ & 2,5 & $\mathbf{0 1}$ & $-2,5$ \\
\hline $\mathbf{0 2}$ & 0,5 & $\mathbf{0 2}$ & 0,0 \\
\hline $\mathbf{0 3}$ & 1,5 & $\mathbf{0 3}$ & 3,0 \\
\hline $\mathbf{0 4}$ & 2,0 & $\mathbf{0 4}$ & 0,0 \\
\hline $\mathbf{0 5}$ & 0,5 & $\mathbf{0 5}$ & 0,0 \\
\hline $\mathbf{0 6}$ & 2,5 & $\mathbf{0 6}$ & 1,0 \\
\hline $\mathbf{0 7}$ & 3,5 & $\mathbf{0 7}$ & $-0,5$ \\
\hline $\mathbf{0 8}$ & 3,0 & $\mathbf{0 8}$ & 2,5 \\
\hline $\mathbf{0 9}$ & 2,0 & $\mathbf{0 9}$ & 2,5 \\
\hline $\mathbf{1 0}$ & 2,5 & $\mathbf{1 0}$ & $-2,0$ \\
\hline $\mathbf{1 1}$ & 0,0 & $\mathbf{1 1}$ & $-2,0$ \\
\hline $\mathbf{1 2}$ & 2,0 & $\mathbf{1 2}$ & $-2,0$ \\
\hline $\mathbf{1 3}$ & 2,5 & $\mathbf{1 3}$ & 1,0 \\
\hline $\mathbf{1 4}$ & 3,0 & $\mathbf{1 4}$ & $-0,5$ \\
\hline $\mathbf{1 5}$ & 1,5 & $\mathbf{1 5}$ & 2,5 \\
\hline $\mathbf{1 6}$ & 1,5 & $\mathbf{1 6}$ & 4,0 \\
\hline $\mathbf{1 7}$ & $-1,5$ & $\mathbf{1 7}$ & 1,5 \\
\hline $\mathbf{1 8}$ & 4,0 & $\mathbf{1 8}$ & 3,0 \\
\hline $\mathbf{1 9}$ & 3,5 & $\mathbf{1 9}$ & 2,0 \\
\hline $\mathbf{2 0}$ & 2,0 & & \\
\hline $\mathbf{2 1}$ & 1,0 & & \\
\hline $\mathbf{2 2}$ & 3,0 & & \\
\hline $\mathbf{2 3}$ & $-0,5$ & & \\
\hline $\mathbf{2 4}$ & 0,5 & & \\
\hline $\mathbf{2 5}$ & 2,5 & & \\
\hline $\mathbf{2 6}$ & $-1,0$ & & \\
\hline $\mathbf{2 7}$ & 0,0 & & \\
\hline & & & \\
\hline
\end{tabular}


ANEXO 7 - Diferenças da distância CI-C, em milímetros, de cada paciente entre o valor ao início do tratamento e ao final da fase de nivelamento

\begin{tabular}{|l|c|c|c|}
\hline \multicolumn{7}{|c|}{ CI - C } \\
\hline & GRUPO I & \multicolumn{2}{c|}{ GRUPO II } \\
\hline $\mathbf{0 1}$ & $-0,5$ & $\mathbf{0 1}$ & $-2,5$ \\
\hline $\mathbf{0 2}$ & 0,5 & $\mathbf{0 2}$ & $-1,0$ \\
\hline $\mathbf{0 3}$ & 1,0 & $\mathbf{0 3}$ & $-0,5$ \\
\hline $\mathbf{0 4}$ & $-0,5$ & $\mathbf{0 4}$ & 1,0 \\
\hline $\mathbf{0 5}$ & $-1,0$ & $\mathbf{0 5}$ & $-3,0$ \\
\hline $\mathbf{0 6}$ & $-1,0$ & $\mathbf{0 6}$ & $-2,5$ \\
\hline $\mathbf{0 7}$ & $-0,5$ & $\mathbf{0 7}$ & $-0,5$ \\
\hline $\mathbf{0 8}$ & $-2,5$ & $\mathbf{0 8}$ & 1,0 \\
\hline $\mathbf{0 9}$ & $-0,5$ & $\mathbf{0 9}$ & $-3,0$ \\
\hline $\mathbf{1 0}$ & 0,5 & $\mathbf{1 0}$ & 2,0 \\
\hline $\mathbf{1 1}$ & $-1,0$ & $\mathbf{1 1}$ & $-0,5$ \\
\hline $\mathbf{1 2}$ & $-3,0$ & $\mathbf{1 2}$ & 1,5 \\
\hline $\mathbf{1 3}$ & $-2,0$ & $\mathbf{1 3}$ & $-2,0$ \\
\hline $\mathbf{1 4}$ & $-2,0$ & $\mathbf{1 4}$ & 1,5 \\
\hline $\mathbf{1 5}$ & $-1,5$ & $\mathbf{1 5}$ & $-2,0$ \\
\hline $\mathbf{1 6}$ & 2,5 & $\mathbf{1 6}$ & $-2,5$ \\
\hline $\mathbf{1 7}$ & $-1,0$ & $\mathbf{1 7}$ & 1,0 \\
\hline $\mathbf{1 8}$ & $-1,0$ & $\mathbf{1 8}$ & $-1,5$ \\
\hline $\mathbf{1 9}$ & $-1,0$ & $\mathbf{1 9}$ & $-1,0$ \\
\hline $\mathbf{2 0}$ & $-1,0$ & & \\
\hline $\mathbf{2 1}$ & $-0,5$ & & \\
\hline $\mathbf{2 2}$ & $-1,0$ & & \\
\hline $\mathbf{2 3}$ & $-2,0$ & & \\
\hline $\mathbf{2 4}$ & $-1,0$ & & \\
\hline $\mathbf{2 5}$ & $-1,5$ & & \\
\hline $\mathbf{2 6}$ & 0,0 & & \\
\hline $\mathbf{2 7}$ & $-2,5$ & & \\
\hline & & & \\
\hline
\end{tabular}


ANEXO 8 - Diferenças da distância RI-C, em milímetros, de cada paciente entre o valor ao início do tratamento e ao final da fase de nivelamento

\begin{tabular}{|l|c|l|c|}
\hline \multicolumn{5}{|c|}{ RI - C } \\
\hline & GRUPO I & \multicolumn{1}{c|}{ GRUPO II } \\
\hline $\mathbf{0 1}$ & 0,5 & $\mathbf{0 1}$ & 2,5 \\
\hline $\mathbf{0 2}$ & $-0,5$ & $\mathbf{0 2}$ & 1,0 \\
\hline $\mathbf{0 3}$ & $-1,0$ & $\mathbf{0 3}$ & 0,5 \\
\hline $\mathbf{0 4}$ & 0,5 & $\mathbf{0 4}$ & $-1,0$ \\
\hline $\mathbf{0 5}$ & 1,0 & $\mathbf{0 5}$ & 3,0 \\
\hline $\mathbf{0 6}$ & 1,0 & $\mathbf{0 6}$ & 2,5 \\
\hline $\mathbf{0 7}$ & 0,5 & $\mathbf{0 7}$ & 0,5 \\
\hline $\mathbf{0 8}$ & 2,5 & $\mathbf{0 8}$ & $-1,0$ \\
\hline $\mathbf{0 9}$ & 0,5 & $\mathbf{0 9}$ & 3,0 \\
\hline $\mathbf{1 0}$ & $-0,5$ & $\mathbf{1 0}$ & $-2,0$ \\
\hline $\mathbf{1 1}$ & 1,0 & $\mathbf{1 1}$ & 0,5 \\
\hline $\mathbf{1 2}$ & 3,0 & $\mathbf{1 2}$ & $-1,5$ \\
\hline $\mathbf{1 3}$ & 2,0 & $\mathbf{1 3}$ & 2,0 \\
\hline $\mathbf{1 4}$ & 2,0 & $\mathbf{1 4}$ & $-1,5$ \\
\hline $\mathbf{1 5}$ & 1,5 & $\mathbf{1 5}$ & 2,0 \\
\hline $\mathbf{1 6}$ & $-2,5$ & $\mathbf{1 6}$ & 2,5 \\
\hline $\mathbf{1 7}$ & 1,0 & $\mathbf{1 7}$ & $-1,0$ \\
\hline $\mathbf{1 8}$ & 1,0 & $\mathbf{1 8}$ & 1,5 \\
\hline $\mathbf{1 9}$ & 1,0 & $\mathbf{1 9}$ & 1,0 \\
\hline $\mathbf{2 0}$ & 1,0 & & \\
\hline $\mathbf{2 1}$ & 0,5 & & \\
\hline $\mathbf{2 2}$ & 1,0 & & \\
\hline $\mathbf{2 3}$ & 2,0 & & \\
\hline $\mathbf{2 4}$ & 1,0 & & \\
\hline $\mathbf{2 5}$ & 1,5 & & \\
\hline $\mathbf{2 6}$ & 0,0 & & \\
\hline $\mathbf{2 7}$ & 2,5 & & \\
\hline
\end{tabular}




\section{REFERÊNCIAS BIBLIOGRÁFICAS}




\section{REFERÊNCIAS BIBLIOGRÁFICAS *}

1. ACKERMAN, J.L. et al. A controlled light continuous force technique. Amer. J. Orthodont., v.56, n.3, p.233-51, Sept. 1969.

2. ALLEN, W.I. Mandibular stability with the twin-wire appliance. Amer. J. Orthodont., v.52, n.7, p.483-94, July 1966.

3. ANDREWS, L.F. The six keys to normal occlusion. Amer. J. Orthodont., v.62, n.3, p.296-309, Sept. 1972.

4. ANDREWS, L.F. The straight-wire appliance: origin, controversy, commentary. J. Clin. Orthodont., v.10, n.2, p.99-114, Feb. 1976.

5. ANDREWS, L.F. The straight-wire appliance: explained and compared. J. Clin. Orthodont., v.10, n.3, p.174-95, Mar. 1976.

6. ANDREWS, L.F. The straight-wire appliance. Br. J. Orthodont., v.6, n.3, p.125-43, July 1979.

7. ANDREWS, L.F. Straight Wire : The concept and appliance. 1.ed. San Diego, L.A. Wells, 1989.

8. ANGLE, E.H. Treatment of malocclusions of the teeth. 7.ed. Philadelphia, SSWhite, 1907, p.227.

9. ANGLE, E.H. The latest and best in orthodontic mechanism. Dental Cosmos, v.70, n.12, p.1143-58, Dec. 1928.

10. ANGLE, E.H. The latest and best in orthodontic mechanism. Dental Cosmos, v.71, p.260-70, Mar. 1929.

11. BAKER, R.W.; GUAY, A.H.; PETERSON JR, H.W. Current concepts of anchorage management. Angle Orthodont., v.42, n.2, p.129-38, Apr. 1972.

12. BAY, R. Co-report: orthodontic methods - anchorage. Int. Dent. J., v.8, n.2, p.298-9, June 1958.

* Normas recomendadas para uso no âmbito da Universidade de São Paulo, com base no documento "Referências Bibliográficas: exemplos", emanado do conselho Supervisor do Sistema Integrado de Bibliotecas da USP, em reunião de 20 de Setembro de 1990. 
13. BEGG, P.R. Stone age man's dentition. Amer. J. Orthodont., v.40, n.7, p.517-31, July 1954.

14. BEGG, P.R. Differential force in orthodontic treatment. Amer. J. Orthodont., v.42, n.7, p.481-510, July 1956.

15. BENNETT, J.C.; MCLAUGHLIN, R.P. As mecânicas do tratamento ortodôntico e o aparelho pré-ajustado. 1.ed. São Paulo, Artes Médicas, 1994.

16. BERGERSEN, E.O. A cephalometric study of the clinical use of the mandibular labial bumper. Amer. J. Orthodont. v.61, n.6, p.578602, June 1972.

17. BROADBENT, B.H. A new x-ray technique and its application to orthodontia. Angle Orthodont., v.1, n.2, p.45-66, Apr. 1931.

18. BRODIE, A.G. et al. The application of the principles of the edgewise arch in the treatment of class II division 1 malocclusion. Angle Orthodont., v.7, n.1, p.1-14, Jan. 1937.

19. BRODIE, A.G. Does scientific investigation support the extraction of teeth in orthodontic therapy? Amer. J. Orthodont. Oral Surg., v.30, n.8, p.444-60, Aug. 1944.

20. BUCHNER, H.J. Maintaining mandibular anchorage in class II division 1 treatment. Angle Orthodont., v.19, n.4, p.231-49, Oct. 1949.

21. BUCHNER, H.J. Anchorage considerations in the treatment of class II division 1 malocclusions. Angle Orthodont., v.27, n.4, p.217-45, Oct. 1957.

22. BULL, H. Obtaining facial balance in the treatment of Class II, division 1. Angle Orthodont. v.9, p.139-44, 1951.

23. BURSTONE, C.J. Rationale of the segmented arch. Amer. J. Orthodont. v.48, p.805-22, 1962.

24. CAPUTO, A.A.; CHACONAS, S.J.; HAYASHI, R.K. Photoelastic visualization of orthodontic forces during canine retraction. Amer. J. Orthodont., v.65, n.3, p.250-9, Mar. 1974.

25. CAREY, C.W. Light force technique combining the sliding section and laminated arches. Amer. J. Orthodont., v.52, n.2, p.85-102, Feb. 1966. 
26. CASE, S.C. A practical treatise on the technics and principles of the dental orthopedia, and prosthetic correction of the cleft palate. 1.ed. Chicago, C.S. Case, 1908, p.83 e 118.

27. CHUCK, G.C. A consideration on the permanent molars as a source of anchorage. Angle Orthodont. v.7, p.15-21, 1937.

28. CIPRIANO, R.; VIGORITO, J.W.; RINO NETO, J. Estudo do comportamento da ancoragem dos dentes posteriores inferiores durante as fases de nivelamento e retração anterior, empregandose a técnica do arco de canto com braquetes angulados a 3 e 5 graus. Ortodontia, v.22, n.2, p.53-63, Maio/Ago. 1989.

29. COLE, H.J. Certain results of extraction in the treatment of malocclusion. Angle Orthodont., v.18, n.3/4, p.103-13, July/Oct. 1948.

30. COLEMAN, R.E. II: anchorage preparation. Amer. J. Orthodont. Oral Surg., v.29, n.4, p.225-7, Apr. 1943.

31. COSTA NETO, P.L.O. Estatística, São Paulo, Edgar Blücher, 1977, $264 p$.

32. DAGUE, A.B.C. Change in position of mandibular first molar as an index of anchorage stability. Amer. J. Orthodont., v.50, n.10, p.781-2, Oct. 1964. /Abstract/

33. DENHOLTZ, M.A. A method of harnesing lip pressure to move teeth. J. Amer. Soc. Orthodont. v. 1, n.2, p.16-35, Dec. 1963.

34. DOWNS, W.B. A study in dental arch length. Angle Orthodont., v.10, n.2, p.78-93, Apr. 1940.

35. EPSTEIN, W.N. Analysis of changes in molar relationships by means of extra-oral anchorage (head-cap) in treatment of malocclusion. Angle Orthodont., v.18, n.3/4, p.63-9, July/Oct. 1948.

36. FOGEL, M.S. A cephalometric assessment of prepared mandibular anchorage. Amer. J. Orthodont., v.43, n.7, p.511-36, July 1957.

37. FOGEL, M.S.; MAGILL, J.M. The combination technique: a system of controlled light-wire therapy. Amer. J. Orthodont., v.49, n.11, p.801-25, Nov. 1963.

38. FREEMAN, R.S. Are class II elastics necessary? Amer. J. Orthodont., v.49, n.5, p.365-85, May 1963. 
39. FREITAS, M.R. Estudo cefalométrico da ancoragem inferior, em pacientes tratados com a técnica de Martins e com preparo de ancoragem (Tweed): estudo analitico e comparativo. Bauru, 1982. Tese (Doutorado) - Faculdade de Odontologia de Bauru, Universidade de São Paulo.

40. GIANELLY, A. Mandibular cervical traction in the treatment of class I malocclusions. Amer. J. Orthodont., v.60, n.3, p.257-63, Sept. 1971.

41. GOLDSTEIN, A.; MYER, E. Further studies in class II treatment. Angle Orthodont., v.10, n.1, p.14-23, Jan. 1940.

42. GUAY, A.H.; BAKER, R.W. A roentgenographic cephalometric evaluation of anchorage management in maximum anchorage cases. Amer. J. Orthodont., v.53, n.2, p.148, Feb. 1967. /Abstract/

43. GUERRERO, J.J. Posterior movement of buccal segments. Amer. J. Orthodont., v.45, n.2, p.125-30, Feb. 1959.

44. HERZBERG, B.L. The Tweed formula, anchorage preparation and facial esthetics. Angle Orthodont., v.24, n.3, p.170-7, July 1954.

45. HIGLEY, L.B. Some thoughts on cephalometrics and anchorage. Amer. J. Orthodont., v.36, n.2, p.135-47, Feb. 1950.

46. HIGLEY, L.B. Anchorage in orthodontics. Amer. J. Orthodont., v.46, n.6, p.456-65, June 1960.

47. HOLDAWAY, R.A. Bracket angulation as applied to the edgewise appliance. Angle Orthodont. v.22, p.227-36, 1952.

48. HOPKINS, S.C. Inadequacy of mandibular anchorage. Amer. J. Orthodont., v.41, n.9, p.691-704, Sept. 1955.

49. HOPKINS, S.C. Inadequacy of mandibular anchorage: five years later. Amer. J. Orthodont., v.46, n.6, p.440-55, June 1960.

50. HUETTNER, R.J.; WHITMAN, C.L. Tissue changes occuring in the Macaque rhesus monkey during orthodontic movement. Amer. J. Orthodont. v.44, p.328-45, 1958.

51. INTERLANDI, S. Ortodontia : bases para iniciação, São Paulo, Artes Médicas, 1977. P.129 e 159. 
52. JARABAK, J.R. Development of a treatment plan in the light of one's concept of treatment objectives. Amer. J. Orthodont., v.46, n.7, p.481-514, July 1960.

53. JOHNSON, J.E. A new orthodontic mechanism: the twin wire automatic appliance. J. Amer. Dental. Assoc., v. 19, n.6, p.9971011 , June 1932.

54. JOHNSTON JUNIOR., L.E.; LIN, S.S.; PENG, S.J. Anchorage loss: a comparative analysis. J. Charles Tweed Int. Found., v.16, p.237, Apr. 1988.

55. KANTER, F. Mandibular anchorage and extraoral force. Amer. J. Orthodont., v.42, n.3, p.194-208, Mar. 1956.

56. KESLING, P.C. Causes of loss of anchorage in $1^{\text {st }}$ and $2^{\text {nd }}$ stages. Begg J. Orthodont. v.2, n.1, p.23-30, Apr. 1963.

57. KLOEHN, S.J. Guiding alveolar growth and eruption of teeth to reduce treatment time and produce a more balanced denture and face. Angle Orthodont., v.17, n.1/2, p.10-33, Jan./Apr. 1947.

58. KLOEHN, S.J. Mixed dentition treatment. Angle Orthodont., v.20, n.2, p.75-96, Apr. 1950.

59. KLOEHN, S.J. Evaluation of cervical anchorage force in treatment. Angle Orthodont., v.31, n.2, p.91-104, Apr. 1961.

60. LEWIS, P.D. Space closure in extraction cases. Amer. J. Orthodont., v.36, n.3, p.172-91, Mar. 1950.

61. MARINHO, A.V. Estudo comparativo entre duas técnicas de preparo de ancoragem : arco de trabalho e braquetes angulados. São José dos Campos, 1973. Tese (Doutorado).

62. MARTINS, D.R.; INTERLANDI, S.; ALMEIDA, R.R. Estudo do preparo de ancoragem no tratamento ortodôntico por meio de implantes metálicos. Ortodontia, v.11, n.3, p.169-75, Set./Dez. 1978.

63. MAZZEI, G. Cephalometrical evaluation of the effect of class III and class II elastics during treatment of class I and class II extraction cases. Amer. J. Orthodont., v.48, n.6, p.472, June 1962. /Abstract/ 
64. McLAUGHLIN, R.P.; BENNETT, J.C. Anchorage control during leveling and aligning with a preadjusted appliance system. J. Clin. Orthodont., v.25, n.11, p.687-96, Nov. 1991.

65. MERRIFIELD, L.L.; CROSS, J.J. Directional forces. Amer. J. Orthodont., v.57, n.5, p.435-64, May 1970.

66. MOYERS, R.E.; HIGLEY, L.B. The stabilizing plate: an adjunct to orthodontic therapy. Amer. J. Orthodont., v.35, n.1, p.54-60, Jan. 1949.

67. NANCE, H.N. The limitations of orthodontic treatment (II: diagnosis and treatment in the permanent dentition) Amer. J. Orthodont. Oral Surg., v.33, n.5, p.253-301, May 1947.

68. OLIVER, O.A. et al. Labio-lingual appliance in present day orthodontic treatment. Dent. J. Aust. v.26, n.2, p.69-74, Apr. 1954.

69. PARROT JR., GH. Erikson's technique with the Universal appliance: Extractions indicated. Amer. J. Orthodont., v.43, n.5, p.261-84, Apr. 1958.

70. PAULSON, R.C.; SPEIDEL, T.M.; ISAACSON, R.J. A laminagraphic study of cuspid retraction versus molar anchorage loss. Angle Orthodont., v.40, n.1, p.20-7, Jan. 1970.

71. PREZZANO, W.J. Anchorage and the mandibular arch. Amer. J. Orthodont., v.37, n.9, p.688-97, Sept. 1951.

72. REITAN, K. Bone formation and resorption during reversed tooth movement. In: KRAUS, B.S.; REIDEL, R.A. Vistas in orthodontics. Philadelphia, Lea\&Febiger, 1962, p.69-84.

73. RENFROE, E.W. The factor of stabilization in anchorage. Amer. J. Orthodont., v.42, n.12, p.883-97, Dec. 1956.

74. RICKETTS, R.M. Bioprogressive therapy as an answer to orthodontic needs Part I. Amer. J. Orthodont., v.70, n.3, p.241-68, Sept. 1976.

75. RICKETTS, R.M. Bioprogressive therapy as an answer to orthodontic needs: part II. Amer. J. Orthodont., v.70, n.4, p.359-97, Oct. 1976.

76. RIZZATTO, R. Estudo comparativo da ancoragem mandibular em função da extensão da bandagem do arco dentário inferior. Ortodontia, v.10, n.3, p.171-9, Set./Dez. 1977. 
77. ROBINSON, apud BENNETT, J.C.; MCLAUGHLIN, R.P., p. 96.

78. ROHDE, A.C. Fundamentals of anchorage force and movement. Amer. J. Orthodont., v.34, n.10, p.860-7, Oct. 1948.

79. ROTH, R.H. Five year clinical evaluation of the Andrews straight-wire appliance. J. Clin. Orthodont., v.10, n.11, p.836-50, Nov. 1976.

80. ROTH, R.H. The straight-wire appliance: 17 years later. J. Clin. Orthodont., v.21, n.9, p.632-42, Sept. 1987.

81. SALZMANN, J.A. Principles of orthodontics. Philadelphia, Lippincott, 1943, p.546.

82. SANDUSKY JR.,W.C. Orthodontic anchorage. Amer. J. Orthodont., v.37, n.11, p.858-66, Nov. 1951.

83. SCHUDY, F.F. The use of the edgewise mechanism in the treatment of class II division 1 malocclusion. Amer. J. Orthodont., v.40, n.3, p.179-88, Mar. 1954.

84. SHELDEN, F.C. Problem of anchorage in the treatment of malocclusion. J. Amer. Dental Assoc., v.31, n.3, p.222-8, Feb. 1944.

85. STONER, M.M. Past and present concepts of anchorage preparation. Angle Orthodont., v.28, n.3, p.176-87, July 1958.

86. STRANG, R.H.W. Orthodontic anchorage. Angle Orthodont., v.11, n.3, p.173-86, July 1941.

87. STRANG, R.H.W. Treatment problems: their origin and elimination.

Amer. J. Orthodont., v.40, n.10, p.765-74, Oct. 1954.

88. STRANGE, H.E. Some thoughts about anchorage. Amer. J. Orthodont., v.37, n.5, p.324-31, May 1951.

89. SUBTELNY, J.D.; SAKUDA, M. Muscle function, oral malformation and growth changes. Amer. J. Orthodont., v.52, n.7, p.495-517, July 1966.

90. TWEED, C.H. The application of the principles of the edgewise arch in the treatment of Class II, division 1 malocclusions, Part I: the principles and technique of treatment. Angle Orthodont. v.6, p.198-208, 1936. 
91. TWEED, C.H. The application of the principles of the edgewise arch in the treatment of malocclusions: I. Angle Orthodont., v.11, n.1, p.5-11, Jan. 1941.

92. TWEED, C.H. The application of the principles of the edgewise arch in the treatment of malocclusions: II. Angle Orthodont., v.11, n.1, p.12-67, Jan. 1941.

93. TWEED, C.H. Indication for the extraction of teeth in orthodontic procedure. Amer. J. Orthodont. Oral Surg. V.30, p.405-28, 1944.

94. TWEED, C.H. A philosophy of orthodontic treatment. Amer. J. Orthodont. Oral Surg., v.31, n.2, p.74-103, Feb. 1945.

95. TWEED, C.H. The Frankfort-mandibular incisor angle (FMIA) in orthodontic diagnosis, treatment planning and prognosis. Angle Orthodont., v.24, n.3, p.121-69, July 1954.

96. TWEED, C.H. Clinical Orthodontics. Saint Louis, Mosby Company, 1966, p.7-8 e 174-231.

97. VIAZIS, A.D. Bioefficient therapy. J. Clin. Orthodont., V.29, n.9, p.552-68, Sept. 1995.

98. VIETH, C.J. A cephalometric appraisal of mandibular molar movement. Amer. J. Orthodont., v.50, n.2, p.142-3, Feb. 1964. /Abstract/

99. WALKER, W.W. A simplified approach to demanding anchorage cases. J. Pract. Orthodont. v.2, n.7, p.354-8, Sept. 1968.

100. WEBER, F.N. The treatment of extraction cases using a modified Johnson twin arch wire technique. Amer. J. Orthodont., v.42, n.3, p.164-75, Mar. 1956.

101. WEIN, S.L. The lingual arch as a source of anchorage in class II treatment (A cephalometric appraisal of forty treated cases). Amer. J. Orthodont., v.45, n.1, p.32-49, Jan. 1959.

102. WILSON, W.L. Variations of labiolingual therapy in class II cases. Amer. J. Orthodont., v.41, n. 11, p.852-71, Nov. 1955.

103. WRIGHT, C.F. A consideration of the anchorage problem. Angle Orthodont., v.9, n.4, p.152-9, Oct. 1939. 
ABSTRACT 


\section{ABSTRACT}

nchorage represents one of the main factors in effective
tooth movement, in order that orthodontic mechanics can be used satisfactorily.

In all existing orthodontic techniques, orthodontists have longed for a mechanical efficiency which is directly proportional to the smallest anchorage loss.

In this research, the objective was to compare the Standard Edgewise Appliance and the Straight Wire Appliance cephalometrically in relationship to the lower anchorage loss during the leveling phase.

This research used a sample of 46 patient cephalographs, which were taken at the beginning of the treatment and at the end of the leveling phase. These patients were divided into two groups according to the technique used for the malocclusion correction.

Group I consisted of 27 patients whose orthodontic correction was accomplished by the Standard Edgewise Appliance. Group II, consisted of 19 patients, whose orthodontic treatment was accomplished by the Straight Wire Appliance.

A specific cephalogram was traced above each cephalograph, to measure anchorage teeth and incisor movements. The cephalometric measurements were the lineal distances $\mathrm{CM}-\mathrm{C}$, RM-C, CI-C and RI-C. 
After the statistical evaluation and with the obtained results, it could be concluded that during the arch leveling phase, in the comparison of the Standard Edgewise Appliance and Straight Wire Appliance, Groups I and II, there was loss of lower anchorage in both groups.

The first lower molar crown exhibited mesial movement which was more evident in group II, but none were statistically significant.

There was loss of anchorage of the first lower molar roots with statistical significance for group I.

The lower incisors exhibited coronary labial tipping without statistical significance, although more evident in group I.

Group II presented less lower incisor root tipping, although not statistically significant. 